\title{
Tropical and Subtropical Forcing of Future Southern Hemisphere Stationary Wave Changes
}

\author{
Matthew Patterson, ${ }^{\mathrm{a}}$ Tim Woollings, ${ }^{\mathrm{a}}$ AND ThOmas J. Bracegirdle ${ }^{\mathrm{b}}$ \\ a Atmospheric, Oceanic and Planetary Physics, University of Oxford, Oxford, United Kingdom \\ ${ }^{\mathrm{b}}$ British Antarctic Survey, Cambridge, United Kingdom
}

(Manuscript received 25 January 2021, in final form 29 June 2021)

\begin{abstract}
Stationary wave changes play a significant role in the regional climate change response in Southern Hemisphere (SH) winter. In particular, almost all CMIP5 models feature a substantial strengthening of the westerlies to the south of Australia and enhancement of the subtropical jet over the eastern Pacific in winter. In this study we investigate the mechanisms behind these changes, finding that the stationary wave response can largely be explained via reductions in the magnitude of the upper-level Rossby wave source over the tropical/subtropical east Pacific. The Rossby wave source changes in this region are robust across the model ensemble and are strongly correlated with changes to low-latitude circulation patterns, in particular, the projected southward migration of the Hadley cell and weakening of the Walker circulation. To confirm our mechanism of future changes, we employ a series of barotropic model experiments in which the barotropic model is given a background state identical to a particular CMIP5 model and an anomalous Rossby wave source is imposed. This simple approach is able to capture the primary features of the ensemble-mean change, including the cyclonic anomaly south of Australia, and is also able to capture many of the intermodel differences. These findings will help to advance our understanding of the mechanisms underpinning SH extratropical circulation changes under climate change.
\end{abstract}

KEYWORDS: Southern Hemisphere; Stationary waves; Climate change; Climate models

\section{Introduction}

Changes to atmospheric circulation are a major source of uncertainty in future projections of precipitation under climate change (Shepherd 2014). Hence, developing a mechanistic understanding of circulation changes will allow the drivers of uncertainty in regional precipitation to be better identified and constrained. General circulation models consistently project a poleward shift and strengthening of the midlatitude westerlies in the Southern Hemisphere (SH) in response to anthropogenic greenhouse gas emissions (e.g., Swart and Fyfe 2012; Barnes and Polvani 2013; Bracegirdle et al. 2013). This change is accompanied by a poleward expansion and weakening of the SH Hadley cell (Lu et al. 2007; Previdi and Liepert 2007), an expansion of the subtropical dry zone (Held and Soden 2006), and intensification of subtropical anticyclones on their poleward side (al Fahad et al. 2020).

However, there are also considerable variations in the patterns of change depending on the season and longitude (Simpson et al. 2014; Song et al. 2018). For instance, the midlatitude jet is expected to undergo a zonally symmetric shift in austral summer (Simpson et al. 2014), whereas in winter the greenhouse gas-induced response is rather zonally asymmetric (Lorenz and DeWeaver 2007; Patterson et al. 2019). Regarding the former, there has been a large amount of discussion about the potential mechanisms underpinning the poleward jet shift;

Supplemental information related to this paper is available at the Journals Online website: https://doi.org/10.1175/JCLI-D-210075.s1.

Corresponding author: Matthew Patterson, matthew.patterson@ physics.ox.ac.uk a comprehensive discussion of these can be found in the review of Shaw (2019).

On the other hand, there has been considerably less discussion of the mechanisms responsible for the zonally asymmetric response in midlatitudes during winter. This paper seeks to explain the mechanisms driving the zonally asymmetric response to climate change in the extratropical SH winter. One factor that is notably different between the winter and summer seasons and that is likely to be related to the different responses is the structure of the mean state. The mean $300-\mathrm{hPa}$ zonal wind for these seasons is shown by unfilled contours in Fig. 1, based on output from models participating in phase 5 of the Coupled Model Intercomparison Project (CMIP5; Taylor et al. 2012). We define austral summer and winter as December-February (DJF) and June-August (JJA), respectively. The circulation in the summer season is characterized by a zonally symmetric, eddy-driven jet stream (Fig. 1a), whereas in winter stationary waves generated in the tropics and modified by Antarctica disrupt the flow, creating a split jet over the extratropical South Pacific (Fig. 1b; Inatsu and Hoskins 2004; Patterson et al. 2020). Comparing the anthropogenically forced changes, shown by colors, the extratropical summertime response is largely zonally symmetric, but in winter the response is more complex. The winter response is manifested as a localized strengthening of the westerlies to the south of Australia (Fig. 1b; Lorenz and DeWeaver 2007; Simpson et al. 2014) and an enhancement of the subtropical jet over the eastern Pacific (Fig. 1b; Chenoli et al. 2017). At the surface, wintertime subtropical highs are projected to intensify in their centers and on their poleward flanks (Li et al. 2013; al Fahad et al. 2020) and the maximum in the midlatitude surface westerlies will likely shift poleward (Bracegirdle et al. 2013) in this season.

Stationary wave changes, that is, variations in the zonally asymmetric component of the circulation, can be generated 


\section{a)}
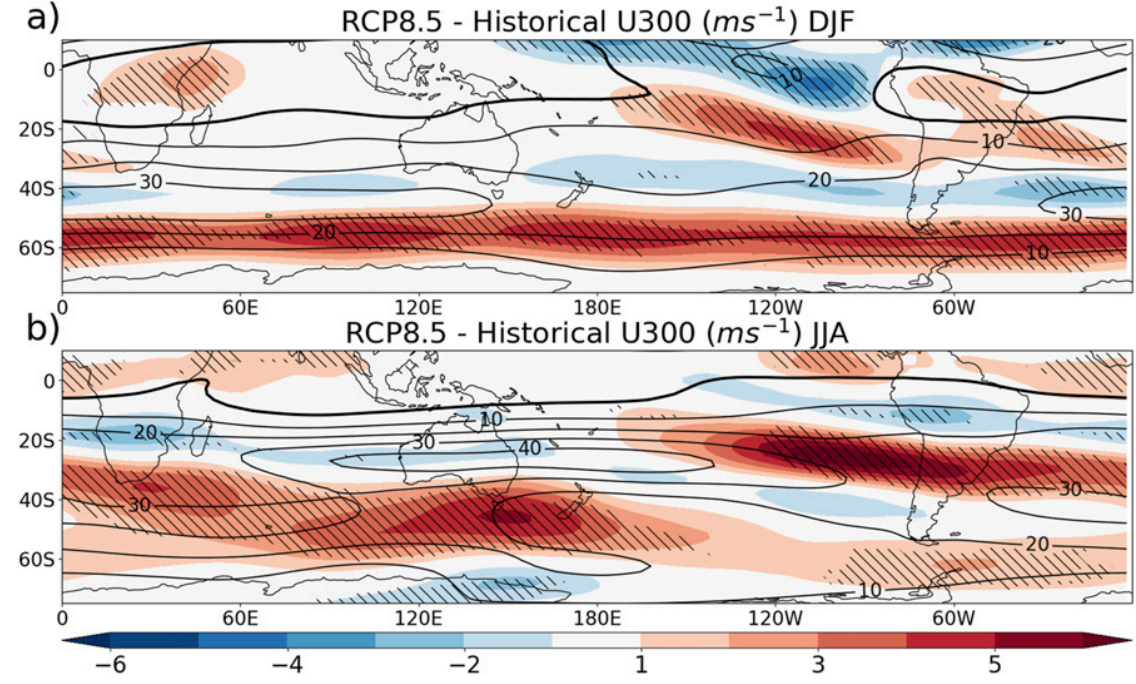

FIG. 1. The 300-hPa zonal wind responses to climate change in (a) austral summer (DJF) and (b) winter (JJA). Colors show the CMIP5 multimodel mean change between the late twentyfirst century under the RCP8.5 scenario (2070-99) and the Historical climatology (1979-2005). Unfilled contours show the Historical climatology with contours drawn every $10 \mathrm{~m} \mathrm{~s}^{-1}$ with thicker contours for zero. Hatching indicates where at least $80 \%$ of the models agree on the sign of the difference.

either through changing the background flow or via modification of the sources of stationary Rossby waves. With respect to the former, Hoskins and Ambrizzi (1993) showed that the stationary wavenumber $K_{S}$ controls the patterns of stationary waves in the extratropics. Slight changes to the background flow (e.g., as a result of changes to the eddy-driven jet) can have a significant impact on $K_{S}$ and thus alter stationary wave patterns (e.g., Joseph et al. 2004; Brandefelt and Körnich 2008; Freitas and Rao 2014; Simpson et al. 2016). Regarding changes to the Rossby wave source, these often occur through changes in sea surface temperatures (SSTs), which alter low-latitude circulation patterns and hence affect upper-level divergence. Waves forced from the tropics and subtropics have been shown to affect present-day SH extratropical circulation in the mean state (Yang and Webster 1990; Lee et al. 2013) and modify it on interannual time scales (e.g., Mo and Higgins 1998; Turner 2004). Rossby wave forcing from the tropics has also been invoked to explain recent trends in West Antarctic surface temperatures (Ding et al. 2011; Li et al. 2014, 2015).

With respect to future climate, changes to the sources of stationary Rossby waves are likely. Comprehensive climate models generally project a future weakening (Held and Soden 2006; Vecchi and Soden 2007; Ma et al. 2012) and eastward shift (Bayr et al. 2014) of the tropical Walker circulation as well as a poleward shift of the Hadley cell edge (Lu et al. 2007; Previdi and Liepert 2007). Those same models also show substantial future changes to tropical rainfall patterns including the "warm-get-wetter" pattern, whereby regions of the tropics that warm faster tend to see larger increases in precipitation (Xie et al. 2010; Ma and Xie 2013). These low-latitude circulation and precipitation changes will alter the upper-level divergence field, changing the sources of stationary Rossby waves.
SSTs are likely to be a stronger driver of these future circulation and precipitation changes than the direct effects of $\mathrm{CO}_{2}$ (Grise and Polvani 2014; He and Soden 2015). Freitas et al. (2017) investigated the influence of different SST changes on the Hadley cell and stationary waves in a warming climate. They found similar stationary wave responses generated by a fully coupled simulation with quadrupled $\mathrm{CO}_{2}$ and a set of atmosphere-only runs with different patterns of raised SSTs. In particular, they found that SST forcing within the deep tropics $\left(5^{\circ} \mathrm{S}-5^{\circ} \mathrm{N}\right)$ provided the largest contribution toward the zonally asymmetric extratropical circulation change and attributed these changes to weakening of upper-level divergence associated with the winter Hadley cell.

In this study, we test the hypothesis that changes to the Rossby wave source can explain the stationary wave response to climate change in the SH winter, seen in CMIP5. We do this via the use of intermodel regression analysis of CMIP5 simulations and through a set of idealized barotropic model runs. With respect to the latter, following Haarsma and Selten (2012), we constrain the barotropic vorticity equation to have the same background state as in the historical climatology for a given model. Next, we force the model with the difference in the Rossby wave source between high greenhouse gas emissions and historical simulations. Finally, we compare the resultant stationary wave response to the change seen in the full CMIP5 models. This simple approach allows us to verify our hypothesis by isolating the key process, namely barotropic Rossby wave dynamics.

This paper is structured as follows: the model data and methods are described in section 2. Following this, in section 3 we investigate the robustness of the stationary wave response across models and whether it depends on SSTs. Then we 
explore the potential mechanisms behind this response using multiple linear regression analysis in section 4 and test these mechanisms using a barotropic model in section 5 . Finally, we provide a discussion of the results and conclusions in section 6 .

\section{Data and methods}

\section{a. Model data}

In this study we utilize monthly mean data from the Historical and representative concentration pathway 8.5 (RCP8.5; Meinshausen et al. 2011) experiments from 36 coupled models from the CMIP5 archive, spanning the years 19792005 and 2070-99 respectively. Additionally, we make use of monthly mean data from AMIP and AMIP4K atmosphereonly experiments (Taylor et al. 2000). The former is forced with observed SSTs and sea ice spanning the period 1978-2008, with the same atmospheric forcings (such as greenhouse gases) as the corresponding coupled Historical experiment. AMIP4K is identical to AMIP except that the SSTs are uniformly raised by $4 \mathrm{~K}$, with no changes to the sea ice. The full list of models employed for this study is given in Tables 1 and 2 in the online supplemental material. Monthly mean ERA-Interim data (Dee et al. 2011) spanning the same period as the Historical experiments (1979-2005) are also used for calculations of model biases in the supplemental material. With the exception of Fig. 1a), all figures are based on SH winter only, where winter is defined as the months of June, July, and August.

\section{b. Indices}

We calculate an index for the Walker circulation as the difference in annual-mean sea level pressure (SLP) between the eastern and western Pacific, following Vecchi and Soden (2007). Spatial mean SLP values for the western and eastern regions are calculated using boxes defined by the latitudes $5^{\circ} \mathrm{S}-5^{\circ} \mathrm{N}$ and the longitudes $80^{\circ}-160^{\circ} \mathrm{E}$ and $80^{\circ}-160^{\circ} \mathrm{W}$, respectively. We define the winter Hadley cell edge, similarly to Kang and Lu (2012) and Vallis et al. (2015), as the latitude at which the 500-hPa meridional overturning streamfunction falls to $10 \%$ of its absolute maximum value between $40^{\circ} \mathrm{S}$ and the equator. Its strength is then defined as the maximum 500-hPa meridional streamfunction value within these latitude bounds.

\section{c. Regression analyses}

Linear least squares regression analysis of a given variable across the CMIP5 models is used to investigate the mechanisms underlying future stationary wave changes. The linear regression model takes the form

$$
Y(m, \theta, \phi)=K(\theta, \phi) X(m)+\epsilon,
$$

in which $Y$ is a model field, such as surface temperature, which is a function of model $(m)$, latitude $(\theta)$, and longitude $(\phi) ; K$ is the regression map to be solved for and $X$ is a particular index (e.g., Hadley cell strength), calculated for each model. Finally, $\epsilon$ is the $y$ intercept, or noise term. This can also be generalized to multiple independent indices $X_{i}$ :

$$
Y(m, \theta, \phi)=\sum_{i} K_{i}(\theta, \phi) X_{i}(m)+\epsilon
$$

The addition of more explanatory variables is likely to improve the model fit to the data, but adding too many such variables can result in overfitting. The adjusted $R$-squared statistic $\bar{R}^{2}$ accounts for spurious increases in the explained variance $R^{2}$ due to increasing the number of explanatory variables. It is defined as follows:

$$
\bar{R}^{2}=1-\left(1-R^{2}\right) \frac{n-1}{n-p-1}
$$

in which $n$ is the number of models and $p$ is the number of explanatory variables.

\section{d. Significance testing}

For figures of regression analyses, we use hatching to indicate the regions for which $p$ values are less than or equal to 0.05 . The $p$ values are calculated, at each grid point, using a Student's $t$ test with the null hypothesis that the regression coefficient is zero. For figures showing multimodel mean differences between present-day and future scenarios, we indicate the level of model agreement on the sign of the change, again using hatching. Hatching is shown for regions where at least $80 \%$ of models agree on the sign of the change. Under the null hypothesis that for a given variable and model the value at each grid point is equally likely to increase or decrease (i.e., a binomial distribution with equally likely outcomes), one could translate this to a twotailed $p$ value of 0.0003 (for 36 models and $80 \%$ model agreement). However, this value may be too low due to the spatial autocorrelation of climate fields. This issue is further discussed by Tebaldi et al. (2011) and Power et al. (2012).

\section{e. Barotropic model}

Following Hoskins and Ambrizzi (1993), the barotropic vorticity equation may be written as

$$
\left(\frac{\partial}{\partial t}+\mathbf{v}_{\psi} \cdot \nabla\right) \zeta=F-\lambda \zeta-\mu \nabla^{4} \zeta,
$$

where $\mathbf{v}_{\psi}$ is the rotational component of the wind, $\zeta$ is the absolute vorticity, and $F$ is a forcing term. The second term on the right-hand side is a linear damping term where $\lambda^{-1}$ is a time scale equal to 10 days and the third term is the hyperdiffusion term, representing the loss of vorticity at small scales, with $\mu=2.4 \times 10^{16} \mathrm{~m}^{4} \mathrm{~s}^{-1}$. Tropical atmospheric circulation is strongly baroclinic, but large-scale Rossby waves generated from low latitudes become equivalent barotropic in midlatitudes (Ambrizzi and Hoskins 1997). Hence, the barotropic vorticity equation can provide insights into extratropical wave propagation.

Following Sardeshmukh and Hoskins (1988), the Rossby wave source $S$ is given by

$$
S=-\nabla \cdot\left(\mathbf{v}_{\chi} \zeta\right)=-\mathbf{v}_{\chi} \cdot \nabla \zeta-\zeta D
$$

where $\mathbf{v}_{\chi}$ is the divergent wind and $D$ is the divergence; $S$ represents the anomalous vorticity in the upper-troposphere generated through absolute vorticity advection and upper-level 
divergence, and provides a diagnostic of anomalous wave forcing. We will refer to the terms on the right-hand side of Eq. (5) as the absolute vorticity advection and vortex stretching terms respectively.

In our experiments, the forcing $F$ is separated into two components:

$$
F=F_{0}+S^{\prime}
$$

Here, $F_{0}$ is a forcing that varies globally as a function of latitude and longitude. It is designed to produce a background state that is identical to the Historical climatology on a given pressure level, for each CMIP5 model. It is calculated through a separate barotropic model run in which the model is strongly relaxed toward the desired climatology. The term $S^{\prime}$ represents the change in the Rossby wave source between the RCP8.5 and Historical simulations; $S^{\prime}$ is set to zero outside of the latitudes between $35^{\circ} \mathrm{S}$ and the equator as extratropical Rossby wave source anomalies are frequently created by wave propagation, but they do not necessarily force it. Including only low-latitude $S^{\prime}$ values avoids directly imposing the midlatitude response that we are attempting to recreate. The inclusion or exclusion of $S^{\prime}$ values to the north of the equator has no effect in the model as upper-level zonal winds are zero or easterly along the equator in JJA, and thus do not permit Rossby wave propagation (Fig. 1b).

The value of $S^{\prime}$ is given by

$$
S^{\prime}=S_{\mathrm{RCP} 8.5}-S_{\mathrm{Hist}}=-\mathbf{v}_{\chi}^{\prime} \cdot \nabla \bar{\zeta}-\overline{\mathbf{v}}_{\chi} \cdot \nabla \zeta^{\prime}-\bar{\zeta} D^{\prime}-\zeta^{\prime} \bar{D},
$$

with primes representing differences between RCP8.5 and the Historical experiments and overbars representing the Historical climatology. In practice, we find that the terms involving $\zeta^{\prime}$ are small compared to those involving $D^{\prime}$ and $\mathbf{v}_{\chi}^{\prime}$ (see Fig. S1 in the online supplemental material) and hence terms involving $\zeta^{\prime}$ have been omitted for the barotropic model calculations. We have also neglected the nonlinear terms as these are also small. Note that $S_{\text {Hist }}$ is not necessarily the same as $F_{0}$; the latter is designed to force the model to have a background state identical to a given model and thus includes the effects of additional processes not included in $S_{\text {Hist }}$.

The background state is chosen to be the vorticity field at $400 \mathrm{hPa}$ given that this level is closest to the equivalent barotropic level (Held et al. 1985). Similar results are obtained if the 500- or 300-hPa levels are used (see Figs. S2 and S3); however, sensitivities to the choice of equivalent barotropic level and forcing region are discussed in section 5. The climatological $S$ peaks at around $200 \mathrm{hPa}$; on the other hand, Haarsma and Selten (2012) noted that the Walker circulation not only weakens in future projections, but also extends upward. This could be problematic for choosing a particular level at which to calculate $S^{\prime}$. Figure S4 shows the multimodel mean of the sector zonal mean $S$ in Historical and RCP8.5 simulations as a function of latitude and pressure, for different ocean basins. It is apparent that $S$ is indeed shifted upward by up to $50 \mathrm{hPa}$ in RCP8.5 runs, hence in our experiments we opt to calculate $S$ as the vertical average between 400 and $70 \mathrm{hPa}$. The barotropic model is integrated at T42 resolution for 100 days. We find that the solution becomes steady after 15 days and we average the solution between days 25 and 100 .

\section{SST patterns and the robustness of the SH stationary wave response}

SST warming patterns represent a significant source of uncertainty in future circulation and precipitation changes (Ma and Xie 2013; Xie 2020). To examine the sensitivity of the $\mathrm{SH}$ stationary wave response to SST warming patterns, we compare changes in the coupled models (RCP8.5-Historical) to atmosphere-only models with the SSTs raised uniformly by $4 \mathrm{~K}$ (AMIP4K-AMIP). The pattern of surface temperature change in RCP8.5 is shown in Fig. 3e, indicating that SST increases by $2-3 \mathrm{~K}$ in most regions, but with enhanced warming over the eastern tropical Pacific and reduced warming over ice-free parts of the Southern Ocean. Zonal mean temperature changes are shown in Figs. 2a,b) along with the corresponding stationary eddy streamfunction change (Figs. 2c,d). Note that in each case the difference in zonal mean temperature/stationary eddy streamfunction for each individual model has been divided by the difference in global mean surface temperature for that model to aid the comparison of patterns in Fig. 2. Uniformly raising SSTs results in a relatively similar pattern of zonal mean temperature change throughout the atmosphere to that in RCP8.5 (Figs. 2a,b). For instance, tropical upper-tropospheric warming is a major feature of both as a result of increased water vapor concentrations reducing the saturated lapse rate (Manabe and Stouffer 1980; Vallis et al. 2015). On the other hand, the larger warming of the Southern Ocean in the AMIP4K runs than in RCP8.5, relative to other regions (Fig. 3e), is likely responsible for the larger SH tropospheric temperature change in Fig. 2b) compared to Fig. 2a).

The stationary wave response patterns are also qualitatively similar (Figs. 2c,d), indicating that the change in RCP8.5 is not fundamentally forced by the pattern of SST change. In both cases, the response does not appear to be a simple weakening (or strengthening) of the climatological pattern (cf. the locations of centroids of unfilled contours and colors; Figs. 2c,d). Regarding similarities between the experiments, the anticyclonic anomaly (blue; anticlockwise flow) over southern Australia and New Zealand, and the cyclonic anomaly (red; clockwise flow) to the south of Australia are both present in both experiments (Figs. 2c,d). Also of note is the relative consistency of the pattern change across models as indicated by regions of hatching, suggesting a common dynamical cause.

While the salient features of the stationary wave patterns are similar between AMIP4K-AMIP and RCP8.5-Historical, there are some inevitable differences in the details such as the emphasis of the former on an anticyclonic anomaly centered on $10^{\circ} \mathrm{S}, 120^{\circ} \mathrm{W}$ and the latter's emphasis on the cyclonic anomaly at $30^{\circ} \mathrm{S}, 90^{\circ} \mathrm{W}$. Furthermore, a robust anticyclonic anomaly is seen over southeast Australia in RCP8.5-Historical, but the change in that region is small and not robust in AMIP4K-AMIP. Some of these differences in the details may result from the different patterns of SST change between AMIP4K and RCP8.5.

Given that we are investigating the robustness of the circulation response, we briefly note that there is no substantial 

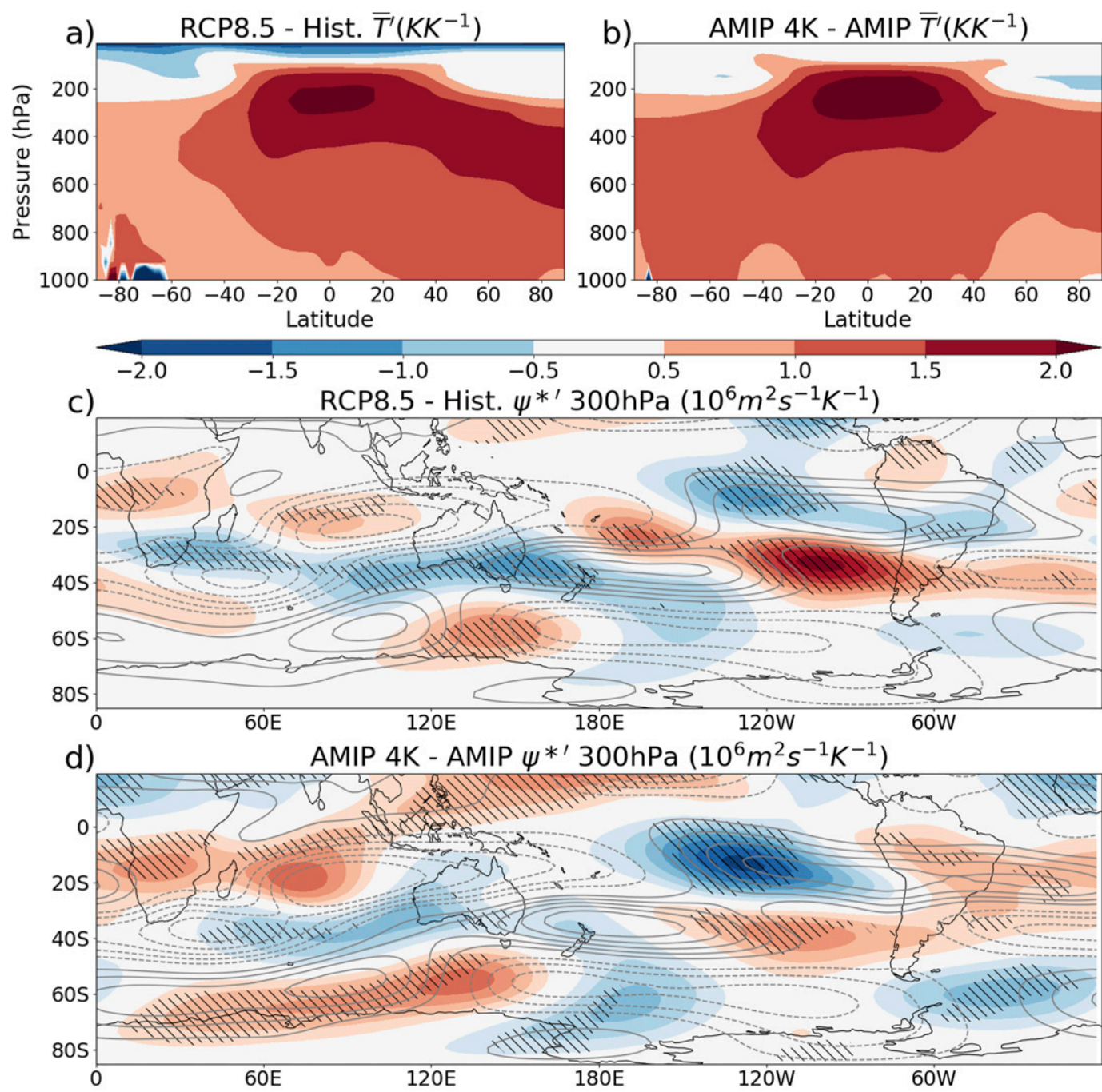

$\begin{array}{llllllll}-1.6 & -1.2 & -0.8 & -0.4 & 0.2 & 0.6 & 1.0 & 1.4\end{array}$

FIG. 2. Multimodel means of (a),(b) zonal mean temperature differences and (c),(d) 300-hPa stationary eddy streamfunction changes (colors) between (a),(c) RCP8.5 and Historical experiments (36 models) and (b),(d) AMIP4K and AMIP experiments (9 models). For each model the difference in zonal mean temperature/stationary eddy streamfunction has been divided by the difference in global mean surface temperature between simulations to make the coupled and atmosphere-only experiments more directly comparable. In (c) and (d), gray contours show the 300-hPa stationary eddy streamfunction climatology for Historical and AMIP experiments, respectively, with a contour interval of $10^{5} \mathrm{~m}^{2} \mathrm{~s}^{-1}$; hatching indicates where at least $80 \%$ of models agree on the sign of the difference.

multimodel mean change in stationary eddy streamfunction over the Amundsen Sea region $\left(65^{\circ} \mathrm{S}, 120^{\circ}-80^{\circ} \mathrm{W}\right.$; Figs. $\left.2 \mathrm{c}, \mathrm{d}\right)$. Examination of individual models (not shown) indicates that this is due to a cancellation of opposite-signed responses in the multimodel mean. Interestingly, we find that the circulation response for a given model is, in this region, correlated with the Historical stationary wave bias (Fig. S5), in agreement with Bracegirdle et al. (2014). This is an important region as melting of West Antarctic glaciers is sensitive to patterns of atmospheric circulation and their interaction with local ocean circulation (Holland et al. 2019). However, further investigation of this model bias-future change relationship is beyond the scope of this study.

\section{Investigating the mechanisms using regression analysis}

In this section, we attempt to understand the mechanisms that give rise to future stationary wave changes with climate change, using simple regression techniques described in section 2. In the introduction, we noted that the mean tropical circulation patterns tend to weaken in response to climate change. This can be seen in Fig. $3 c$ in which colors show the change in 

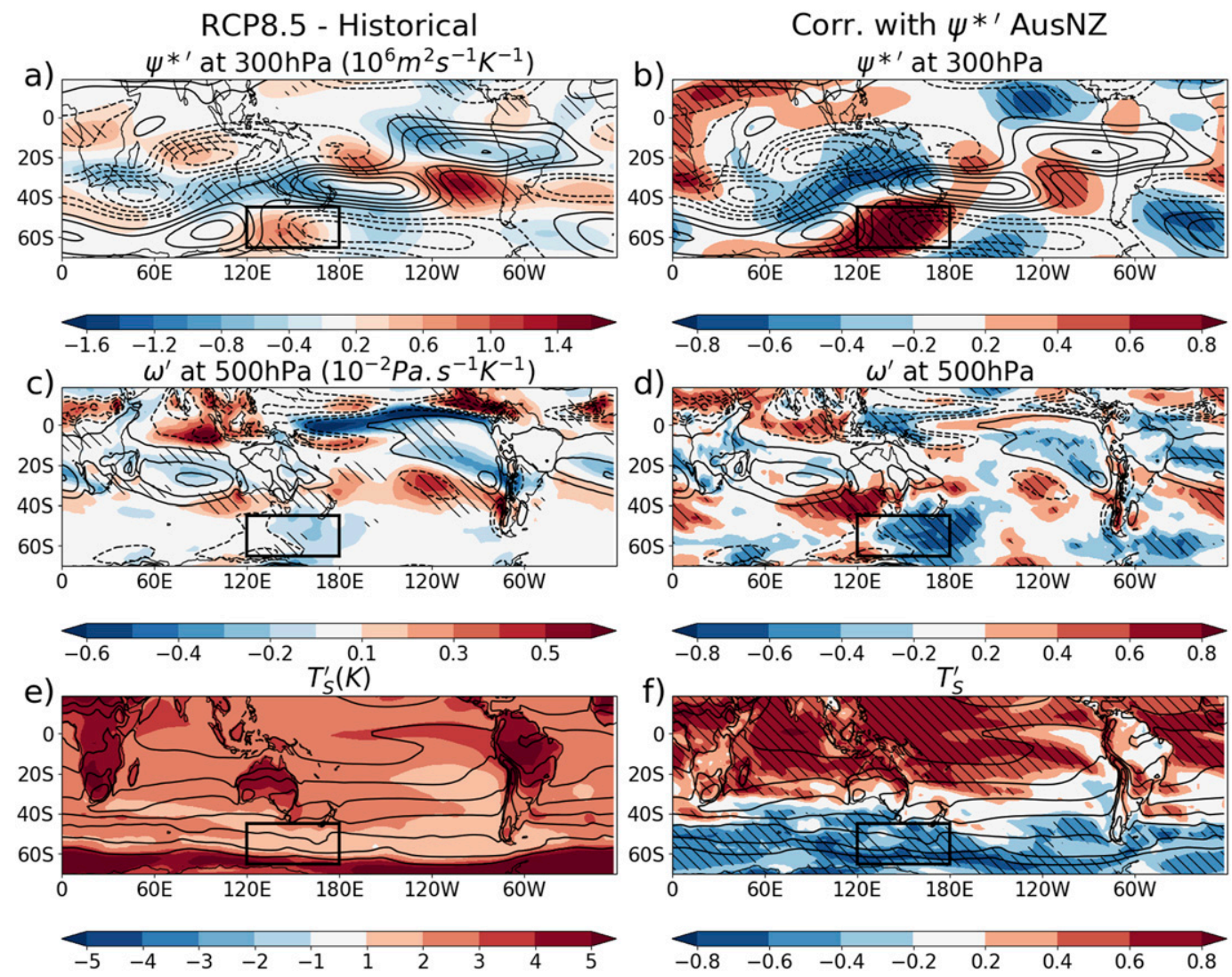

FIG. 3. Multimodel mean differences in (a) 300-hPa stationary eddy streamfunction $\left(\psi^{*}\right)$, (c) 500-hPa vertical velocity $(\omega)$, and (e) surface temperature between RCP8.5 and the Historical simulations. Differences are shown by colors and the Historical climatology is shown by black contours. Climatology contour intervals are (a),(b) $2 \times$ $10^{5} \mathrm{~m}^{2} \mathrm{~s}^{-1}$, (c),(d) $2 \times 10^{-2} \mathrm{~Pa} \mathrm{~s}^{-1}$, and (e),(f) $5 \mathrm{~K}$ beginning at $270 \mathrm{~K}$. In (a) and (c), hatching shows regions in which at least $80 \%$ of models agree on the sign of the difference. Also plotted in (b), (d), and (f) are correlations between the future change in 300-hPa stationary eddy streamfunction in the region shown by the box and the future change in the variable at each grid point. Correlations are shown by colors in (b), (d), and (f), with the Historical climatology shown by contours. The variables and the stationary eddy streamfunction change are both scaled by the global mean warming in each model before correlations are calculated following Zappa and Shepherd (2017). Hatching in (b), (d), and (f) shows where $p$ values are below 0.05 following a Student's $t$ test.

500-hPa vertical velocity and contours indicate the Historical climatology. Across most of the tropics and subtropics, the magnitude of the vertical velocity decreases, with hatching indicating a substantial level of model agreement (Fig. 3c). The ascending branch of the Walker circulation also appears to shift eastward over the Maritime Continent (Fig. 3c).

To relate these changes to the $\mathrm{SH}$ stationary wave change, we take the stationary eddy streamfunction change in the region to the south of Australia in which the circulation becomes anomalously cyclonic (Fig. 3a) and create an index, averaging over $45^{\circ}-65^{\circ} \mathrm{S}, 120^{\circ}-180^{\circ} \mathrm{E}$ (shown by boxes in Fig. 3 ). We then calculate the correlation between the change in this index and the change in stationary eddy streamfunction, vertical velocity and surface temperature at each grid point, across the different CMIP5 models (Figs. 3b,d,f). While this region is only one aspect of the stationary wave change, it is a robust change across models (hatching in Fig. 3a) and of societal importance given the effects on weather over Australia and New Zealand.
Furthermore, the change in this region is fairly strongly correlated with salient features of the mean stationary wave change pattern (Fig. 3b). In the correlation plot the variable and index have again been divided by the global mean surface temperature change, hence the correlations do not arise because of climate sensitivity. The vertical velocity correlation plot (Fig. 3d) shows some spatial correspondence with the multimodel mean change in Fig. 3c) including weakened descent at $20^{\circ} \mathrm{S}$ over the eastern Pacific and Atlantic Oceans and a shifting of the ascending branch of the Walker circulation. There is also a common region of weakened ascent in the subtropical South Pacific centered on $40^{\circ} \mathrm{S}, 120^{\circ} \mathrm{W}$. However, there is no spatial correspondence over the equatorial Pacific (Figs. 3a,b), suggesting that the stationary wave pattern is not solely linked to a uniform slowing down of the mean tropical circulation and other factors may be important.

We next consider the effect of surface temperature changes on the stationary wave response pattern. The experiments of 
Freitas et al. (2017) indicated that tropical SST warming was the driving factor behind the stationary wave response, a finding corroborated by the strong positive correlations in tropical regions in Fig. 3f). SST correlations also show that a stronger north-south SST gradient is associated with a greater cyclonic anomaly south of Australia, which is likely to be related to concomitant changes to the westerly jet (Fig. 3f). Furthermore, the strong correlation between tropical SSTs and future circulation changes south of Australia are consistent with Mindlin et al. (2020), who found a relationship between tropical upper-tropospheric warming and circulation changes in the Australia region. Tropical upper-tropospheric warming is tied to tropical SST changes as the tropical atmosphere closely follows a moist adiabatic lapse rate.

Interestingly, there is also a strong east-west gradient in the magnitude of the SST correlation over the equatorial Pacific (Fig. 3f). Note that this is opposite in sign to the narrow, El Niño-like multimodel mean warming (Fig. 3e). If the stationary wave pattern is strongly controlled by the weakening of the Walker cell, a weakening of the usual east-west SST gradient may be anticipated, but this is the opposite to what Fig. $3 f$ shows. Therefore, Walker cell weakening cannot account for this correlation pattern (Fig. 3f).

On the other hand, Freitas et al. (2017) suggested that the expansion of the Hadley cell may mediate the connection between warming tropical SSTs and the SH stationary wave response. Whether the Hadley cell expands or contracts in response to tropical heating depends critically on the meridional structure of the heating (Lu et al. 2008) with a narrow, El Niño-like heating linked to a contraction of the Hadley cell. Most models project a poleward shift of the Hadley cell edge; given the El Niño-Hadley cell relationship, a more La Niñalike warming may result in a greater Hadley cell expansion. Larger Hadley cell changes may then have a greater effect on the extratropical circulation, for example, through changes to upper-level divergence in the subtropics that would alter the wave forcing or through changing the zonal mean flow in midlatitudes.

To test the effects of changes in the Hadley cell on future circulation changes, we perform a multiple regression of zonal wind and stationary eddy streamfunction changes onto indices for changes in the strength and extent of the SH Hadley cell, and the strength of the Walker cell. We include regressions using a Walker cell index as this could potentially affect the Rossby wave source in the tropics (Haarsma and Selten 2012). The definitions of the indices are described in section 2. Each of the indices used to calculate regression maps has also been multiplied by a factor of -1 to reflect the fact that each of these indices is decreasing and thus to aid comparison with other figures. That is, the SH Hadley cell edge is projected to migrate southward and hence is decreasing in latitude. Therefore, multiplying by -1 means a more positive Hadley cell edge index corresponds to a more poleward shifted Hadley cell edge. Similarly, the Walker and Hadley cells are both projected to decrease in strength (Held and Soden 2006), hence multiplying these indices by -1 means more positive values correspond to a weaker Walker/Hadley cell. Note that the Hadley cell strength and edge changes are positively correlated across models; however, removing the covarying component from one of these two variables before performing the regression does not change the results substantially (not shown).

Circulation changes associated with both the Walker cell and Hadley cell edge (Fig. 4), are similar to elements of the multimodel mean circulation change (Figs. $1 \mathrm{~b}$ and 2c). Regarding the Hadley cell edge, this is associated with a jet strengthening at all longitudes (Fig. 4c, as in Fig. 1b). This is consistent with the work of Ceppi and Hartmann (2013), who found a correlation between the Hadley cell edge and eddy-driven jet speed in the $\mathrm{SH}$, with the eddy-driven jet affecting the Hadley cell edge via modulation of subtropical critical latitudes. It is therefore possible that changes to the midlatitude jet affect the Hadley cell edge, rather than vice versa, or alternatively both the Hadley cell and jet strength may adjust together in response to increasing stability in subtropics, as this shifts the location of the maximum meridional temperature gradient poleward and makes this region less favorable for the development of baroclinic eddies. There are also considerable zonal asymmetries to the Hadley cell edge response, and many of the asymmetric circulation anomalies correspond with the multimodel mean stationary wave pattern in Fig. 2c. These include a pair of cyclonic anomalies over the subtropical Pacific and another cyclonic anomaly to the south of Australia, although the latter is shifted slightly northeastward with respect to the multimodel mean change pattern (Fig. 4d). Future poleward shifting of the Hadley cell is correlated with tropical upper-tropospheric warming (Lu et al. 2008), and hence it is possible that the link between tropical warming and zonally asymmetric circulation changes in the Australia region (Fig. 3f; Mindlin et al. 2020) is mediated by the Hadley cell.

Walker cell changes are also correlated with a cyclonic anomaly to the south of Australia and anomalously anticyclonic flow over Australia (Fig. 4f, as in Fig. 2c) and with the strengthened subtropical jet over the South Pacific. The Walker cell is projected to weaken in both coupled models (e.g., Bayr et al. 2014) and atmosphere-only models (Gastineau et al. 2009) and weakening occurs independent of the pattern of tropical Pacific SST change, although the pattern of SST change may exacerbate the weakening (Ma et al. 2012). If Walker circulation weakening is one of the drivers of future $\mathrm{SH}$ stationary wave changes (and given that this also occurs in experiments with uniformly raised SSTs), then this could explain why a similar stationary wave change is seen in both the RCP8.5 and AMIP4K experiments (Figs. 2c,d).

On the other hand, circulation changes associated with Hadley cell strength do not resemble the multimodel mean changes (Fig. 2c) and are largely opposite in sign to those changes (Figs. 4a,b). For instance the anomalously anticyclonic flow over the subtropical South Pacific in Fig. $4 \mathrm{~b}$ is a region where the future change is cyclonic (Fig. 2c). This suggests that Hadley cell weakening is not a key driver of multimodel mean SH stationary wave changes. Taken together, variations in these three indices account for more than $60 \%$ of the adjusted variance in future zonal wind changes to the south of Australia and over $40 \%$ of the stationary wave change over large parts of the tropical and subtropical South Pacific (Figs. 4g,h). 

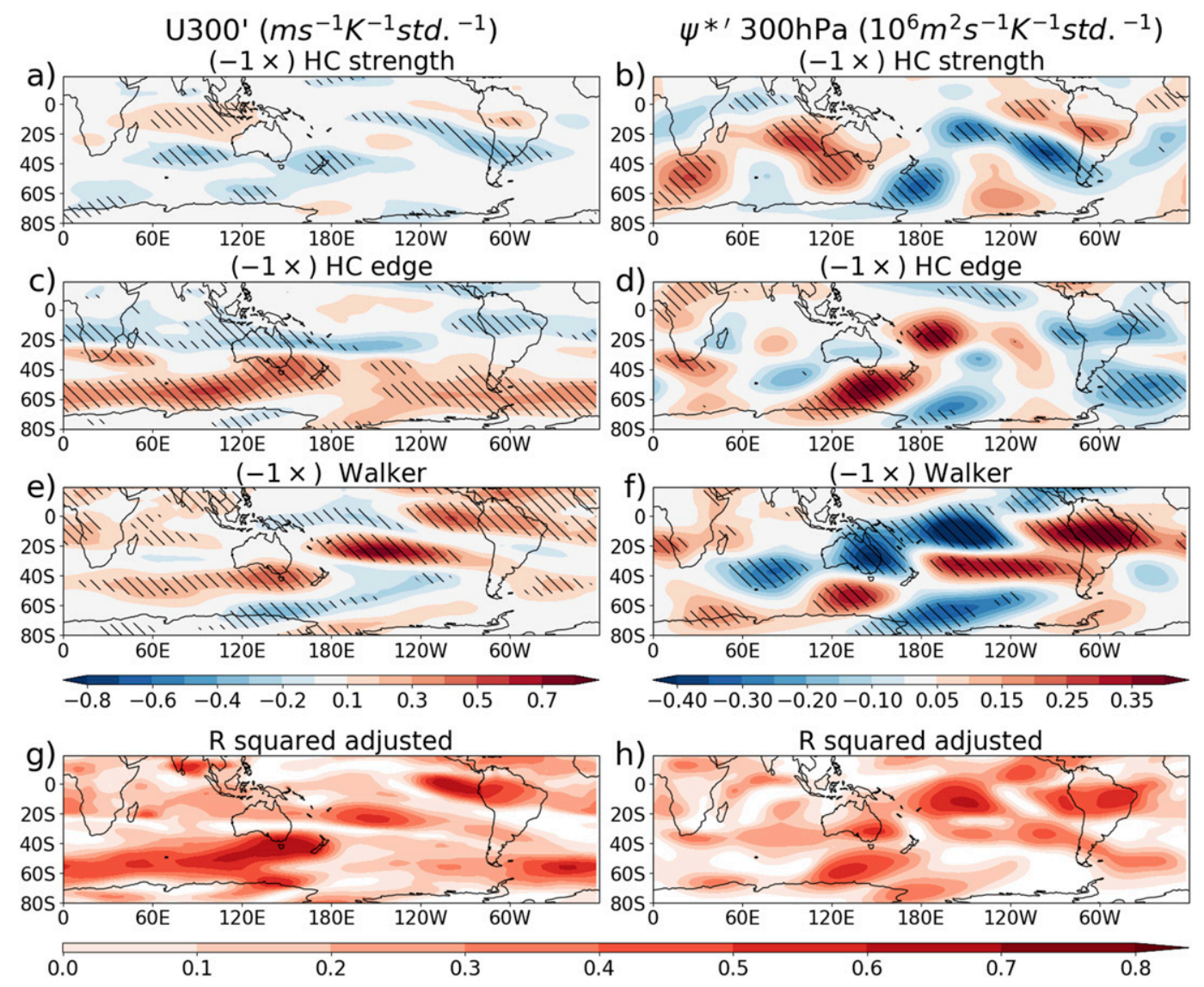

FIG. 4. (a)-(f) Multiple linear regression analysis in which $300-\mathrm{hPa}$ zonal wind and stationary eddy streamfunction changes in each model between RCP8.5 and Historical simulations are regressed onto the change in the Walker circulation and Hadley cell indices. The zonal wind, stationary eddy streamfunction, and indices have all been divided by the global mean warming between RCP8.5 and Historical runs for each model. The indices have also been standardized and multiplied by a factor of -1 . The units for the plots are therefore (a),(c),(e) $\mathrm{m} \mathrm{s}^{-1} \mathrm{~K}^{-1}$ per standard deviation of index change and (b),(d),(f) $\mathrm{m}^{2} \mathrm{~s}^{-1} \mathrm{~K}^{-1}$ per standard deviation of index change. Hatching shows where $p$ values are below 0.05 following a Student's $t$ test. Adjusted $R$-squared values are shown for (g) the zonal wind and (h) stationary eddy streamfunction regression models.

We now seek to investigate the underlying mechanisms more directly and advance the hypothesis that the correlations between SH winter circulation changes and the Hadley and Walker cells occur through $S$ changes. Figure 5a shows the multimodel mean $S$ climatology in which $S$ has been vertically averaged between 400 and $70 \mathrm{hPa}$. Due to the dependence of absolute vorticity $\zeta$ on the Coriolis parameter, $S$ is generally weak in the tropics, but large in the subtropics. Notable regions of strong $S$ include negative regions at $30^{\circ} \mathrm{S}$ over the Indian and Atlantic Oceans associated with large-scale subsidence, and a positive-negative dipole between $20^{\circ}$ and $40^{\circ} \mathrm{S}$ over the eastern Pacific. The climatological positive-negative dipole is caused by divergence on the equatorward side of the subtropical jet exit and convergence on the poleward side.

In terms of future changes in $S$, these are characterized by a general reduction in magnitude across the tropics and subtropics (cf. Figs. 5a,b). This pattern is particularly pronounced over the eastern Pacific, and is, in this region, consistent across models (hatching). In spite of the strong correlation between
SH stationary wave changes and the eastward shift of the ascending branch of the Walker cell (Figs. 3c,d), $S^{\prime}$ is small in this region. This suggests that if the shifting of the ascending Walker cell branch is important for the stationary wave change, this does not occur via local changes to $S$, although it could indirectly affect $S$ near the descending branch.

The precise reason for the consistent eastern Pacific response is not obvious, but could be related to the strengthened subtropical jet at $25^{\circ} \mathrm{S}, 140^{\circ} \mathrm{W}$, which would alter the upperlevel divergence (Fig. 1b). This subtropical jet change may in turn arise from warmer tropical Pacific SSTs warming the tropical troposphere and thus increasing the meridional temperature gradient (Fig. 2a), thereby strengthening the subtropical jet through thermal wind balance. Alternatively, the change in $S$ could be a local manifestation of Hadley cell expansion and weakening, which would again modify upper-level divergence. However, it is unclear why similar changes are not seen elsewhere in the $\mathrm{SH}$ subtropics. For example, the Indian Ocean, which has large $S$ values in the Historical climatology, 

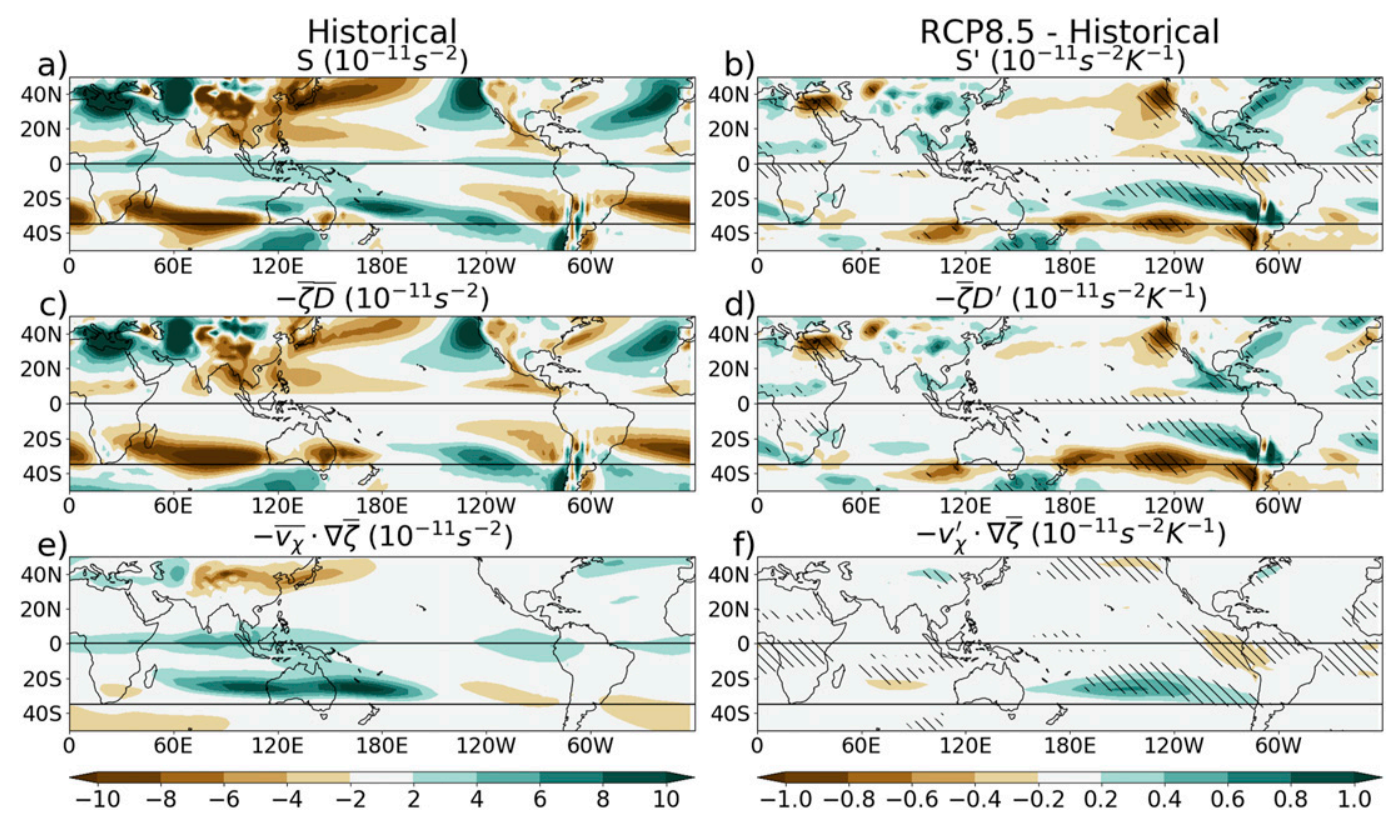

FIG. 5. Multimodel mean Rossby wave source, vertically averaged between 400 and $70 \mathrm{hPa}$ in (a) the Historical experiments and (b) difference between RCP8.5 and Historical experiments. The Historical climatology of (c) vortex stretching and (e) vorticity advection terms are also shown, along with the future changes for (d) vortex stretching and (f) vorticity advection terms. In each plot the horizontal black lines indicate the region over which the $S$ forcing is applied in the barotropic model experiments and hatching in (b), (d), and (f) shows where at least $80 \%$ of models agree on the sign of the difference.

shows no consistent changes (Fig. 5b). This is not to say that there are not changes to Indian Ocean $S$ in individual models, but there is no consistent response across models.

Breaking these changes down further into the vortex stretching (Figs. 5c,d) and advection (Figs. 5e,f) terms, the pattern of eastern Pacific $S$ changes is dominated by reductions in the magnitude of the vortex stretching term, with some compensation in the subtropics by a more positive advection term. Again, hatching over the Pacific indicates substantial model agreement on the sign of the change.

To confirm the link between future changes to the Hadley and Walker cells and Rossby wave source changes, we again utilize multiple linear regression as in Fig. 4. Figure 6 shows regressions of the Hadley and Walker cell indices onto $S^{\prime}$. Both the southward shift of the Hadley cell edge and weakening of Walker cell are associated with $S^{\prime}$ patterns that contribute to the multimodel mean change. Specifically, weakening of the Walker cell index is linked to positive $S^{\prime}$ over $20^{\circ}-30^{\circ} \mathrm{S}, 160^{\circ}$ $80^{\circ} \mathrm{W}$ and negative $S^{\prime}$ to the north of New Zealand (Figs. $5 \mathrm{~b}$ and 6c). A more southward Hadley cell shift is correlated with a negative-positive-negative pattern of $S^{\prime}$ across the subtropical Pacific (Fig. 6b), which corresponds to the centers of action of the multimodel mean change in Fig. 5b) at $180^{\circ} \mathrm{E}$ and $120^{\circ} \mathrm{W}$ and a local minimum in between. The change in Hadley cell strength does have an effect on $S^{\prime}$, but it does not capture many of the features of the multimodel mean change (Figs. 5b and 6a). Interestingly, the combination of these three indices explains a large part of the variance over the subtropical Pacific (50\%-60\% in places), but much less over the Indian and
Atlantic Oceans (Fig. 6d). This suggests that the reason for the consistent Rossby wave source change over the South Pacific region (Fig. 5b) is due to the strong influence of Hadley cell edge and Walker cell changes over this region.

Considering the consistency of $S^{\prime}$ over the eastern Pacific, we now use the multiple linear regression method to connect Pacific $S^{\prime}$ to stationary wave changes. Given that $S^{\prime}$ forms a meridional dipole over the eastern Pacific, we create two indices of the mean $S$ change defined by the regions $30^{\circ}-35^{\circ} \mathrm{S}$, $160^{\circ} \mathrm{E}-80^{\circ} \mathrm{W}$ and $15^{\circ}-25^{\circ} \mathrm{S}, 150^{\circ}-80^{\circ} \mathrm{W}$, labeled SP1 and SP2 respectively. Note that these two indices are slightly negatively correlated $(R=-0.24, p$ value $=0.16)$. The $S$ change in the SP1 index (Fig. 7c) has been multiplied by a factor of -1 to give it the same sign as the multimodel mean change (Fig. 7b). The stationary wave pattern associated with SP1 $S^{\prime}$ consists of a quadrupole of anomalies over the subtropical Pacific, a cyclonic anomaly at $65^{\circ} \mathrm{S}, 120^{\circ} \mathrm{E}$, and an anticyclonic anomaly near the Drake Passage (Fig. 7e). SP2 is characterized by a zonal anticyclonic-cyclonic pair of anomalies in the tropical Pacific, anticyclonic flow over Australia, and a cyclonic anomaly to the south of Australia (Fig. 7f). Notably, this regression pattern bears some resemblance to the Walker cell regression pattern in Fig. 4f, particularly in the tropical and subtropical Pacific and south of Australia. Regarding the direction of causality, the SP2 $\psi^{* \prime}$ regression map features an anticyclonic anomaly over Australia, upstream of the boxed region, which at first glance looks like it could be driving the SP2 $S^{\prime}$ change. However, our barotropic model experiments (section 5) will show that this upstream 


$$
S^{\prime} \text { regression }\left(10^{-11} \mathrm{~s}^{-2} \mathrm{~K}^{-1} \mathrm{std} .{ }^{-1}\right)
$$
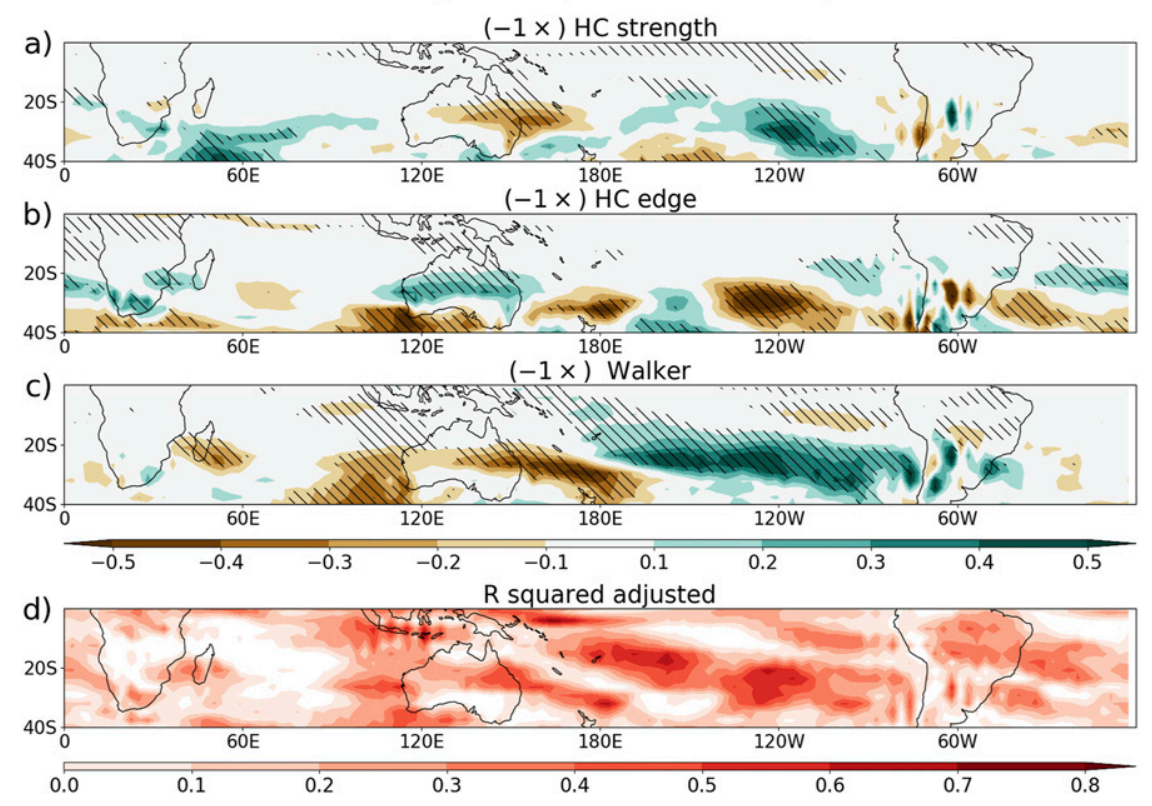

FIG. 6. (a)-(c) Multiple linear regression analysis in which $S^{\prime}$ in each model is regressed onto the change in the Walker circulation and Hadley cell indices. $S^{\prime}$ and indices have all been divided by the global mean warming between RCP8.5 and Historical runs for each model. The indices have also been standardized and multiplied by a factor of -1 . The units for (a)-(c) are $10^{-11} \mathrm{~s}^{-2} \mathrm{~K}^{-1}$ per standard deviation of index change. Hatching shows where $p$ values are below 0.05 following a Student's $t$ test. (d) Adjusted $R$-squared values for the multiple regression model.

anomaly is not necessary to drive the SH stationary wave response.

In Figs. 7e and $7 \mathrm{f}$ we have multiplied the regression coefficients by the mean change in the $S$ index such that they have the same units as the stationary eddy streamfunction change (Fig. 7g) and thus are more easily comparable. If we then sum the regression patterns in Figs. 7e and 7f, it can be seen that the resulting pattern bears a strong resemblance to the multimodel mean change (Figs. 7g,h), providing strong evidence that the South Pacific $S$ forcing (from the SP1 and SP2 regions) is responsible for these changes. For example, the cyclonic anomaly south of Australia and anticyclonic flow over Australia is well captured in both magnitude and location, as is the anticyclonic anomaly near the Drake Passage. The two Pacific $S$ change indices explain up to $60 \%$ of the intermodel adjusted variance over the tropical and subtropical Pacific and up to $30 \%$ in the midlatitudes (Fig. 7i). This is lower than for the Walker and Hadley cell indices in Figs. 4g,h), likely in part because much smaller areas are used to define the SP1/2 indices. Although Pacific $S^{\prime}$ explains the multimodel mean stationary eddy streamfunction change well (Fig. 7h), variations in Indian and Atlantic Ocean $S^{\prime}$ between models will likely contribute to the total variance.

In summary, the CMIP5 models show a consistent weakening of the climatological $S$ dipole pattern over the eastern Pacific (Fig. 5b). A multiple linear regression model including changes to both the Hadley cell edge and Walker cell indicates that these indices are related to the multimodel mean $S^{\prime}$ pattern (Figs. 6b,c). The Hadley and Walker cell indices also explain a large amount of the variance in stationary wave changes (Fig. 4). It therefore appears plausible that changes to the Walker and Hadley cells lead to a change in $S$ over the eastern Pacific, which subsequently results in an anomalous stationary wave pattern in the $\mathrm{SH}$.

\section{Barotropic modeling experiments}

To further test the effect of South Pacific $S^{\prime}$ on SH stationary waves, in this section we model the stationary wave changes using a barotropic model, forced with tropical and subtropical $S^{\prime}$. The simplicity of the barotropic model allows us to examine our proposed mechanism by isolating the most important process, namely barotropic Rossby wave dynamics. The procedure for each CMIP5 model is as follows. The forcing required to exactly recreate the Historical climatological state (on a particular pressure level, here $400 \mathrm{hPa}$ ) from that model is calculated. Following this, $S^{\prime}$ is calculated and imposed on top of the forcing used to recreate the background state. Note that $S^{\prime}$ is only nonzero from $0^{\circ}$ to $35^{\circ} \mathrm{S}$ to avoid putting into the model the circulation patterns that we are attempting to recreate.

Figure 8 shows the multimodel mean of all barotropic model experiments (Figs. 8b,c) in comparison with the multimodel mean change in the full CMIP5 models (Fig. 8a). Note that this 

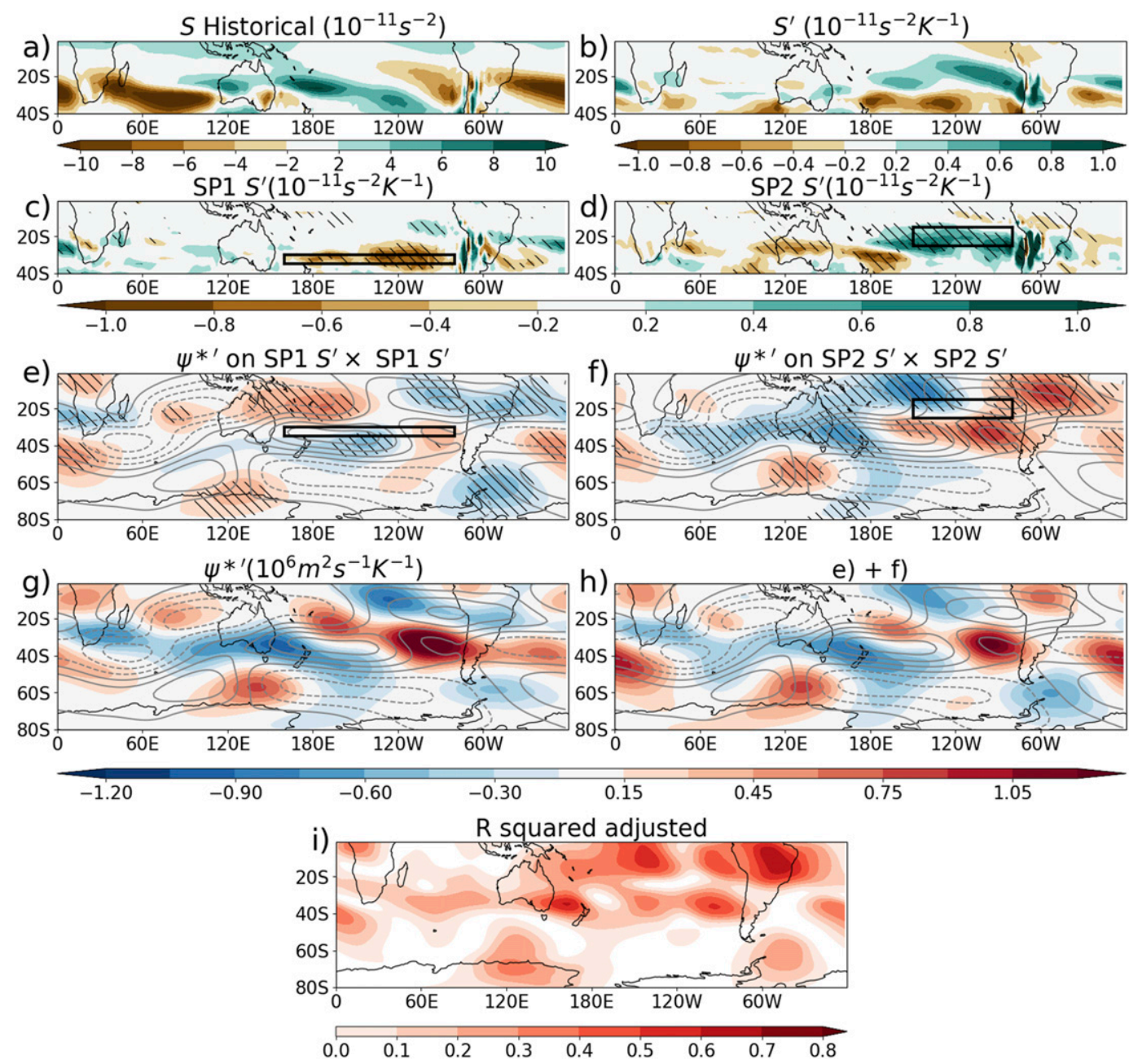

FIG. 7. Multiple linear regression analysis of stationary eddy streamfunction changes with respect to $S$ indices: (a) the multimodel mean Historical $S$ climatology, (b) the change in $S$ (RCP8.5 - Historical; i.e., $S^{\prime}$, but divided by the global mean surface warming in each model), (c) $S^{\prime}$ regressed onto the SP1 index, and (d) $S^{\prime}$ regressed onto the SP2 index. (e),(f) Colors indicate regression coefficients for the multiple regression model of stationary eddy streamfunction changes regressed onto the SP1 and SP2 indices respectively. However, the value at each grid point has been multiplied by the mean of the respective SP1/SP2 index such that the units are $\mathrm{m}^{2} \mathrm{~s}^{-1} \mathrm{~K}^{-1}$. (g) The multimodel mean stationary eddy streamfunction change. (h) The sum of (e) and (f). Gray contours in (e)-(h) indicate the Historical climatology with a contour interval of $10^{5} \mathrm{~m}^{2} \mathrm{~s}^{-1}$. (i) Adjusted $R$-squared values for the multiple regression model in (e) and (f). Hatching in (c)-(f) shows where $p$ values are below 0.05 following a Student's $t$ test and the SP1 and SP2 regions are indicated by the black boxes in (c)-(f).

has been plotted on a polar map projection to emphasize the extratropical response to lower-latitude forcing. The figures show values to approximately $10^{\circ} \mathrm{S}$ (roughly the northern tip of Australia). The barotropic model experiments including forcings over all longitudes capture several of the salient features of the full CMIP5 models, most notably the cyclonic anomaly to the south of Australia (Fig. 8b). Intriguingly, imposing only the forcing over the South Pacific (defined by longitudes $180^{\circ}$ to $80^{\circ} \mathrm{W}$ ) results in a pattern that corresponds more closely to the full CMIP5 models (Fig. 8c). Once again, the cyclonic anomaly south of Australia is captured, but so is the anticyclonic region to its north, while an anticyclonic anomaly extends through the
Drake Passage, as in the full models. In both sets of barotropic model experiments, a cyclonic anomaly is found over the subtropical South Pacific, as in the full models, although it should be noted that this anomaly is almost directly imposed by the anomalous $S$ in this region.

The choice of $35^{\circ} \mathrm{S}$ as the poleward bound of the imposed forcing is a compromise between including as much of the low-latitude $S^{\prime}$ pattern as possible, but not reaching into the midlatitudes. To test the sensitivity to the latitude of the poleward bound, we also perform experiments for the latitudes $20^{\circ}, 30^{\circ}$, and $40^{\circ} \mathrm{S}$. These show that the spatial pattern is very similar for poleward bounds at $30^{\circ}, 35^{\circ}$, and $40^{\circ} \mathrm{S}$ and a larger 
a)

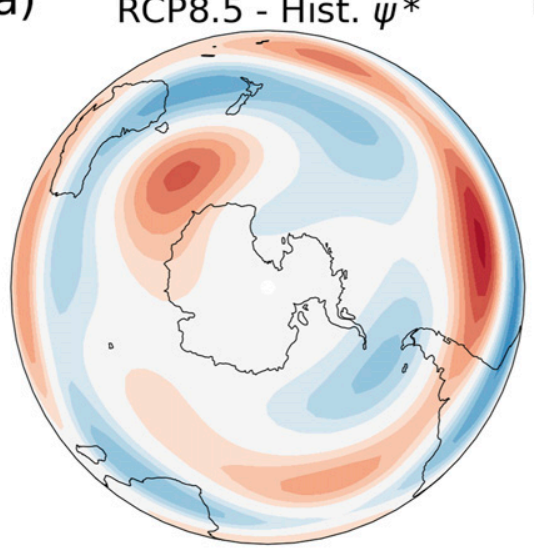

b)

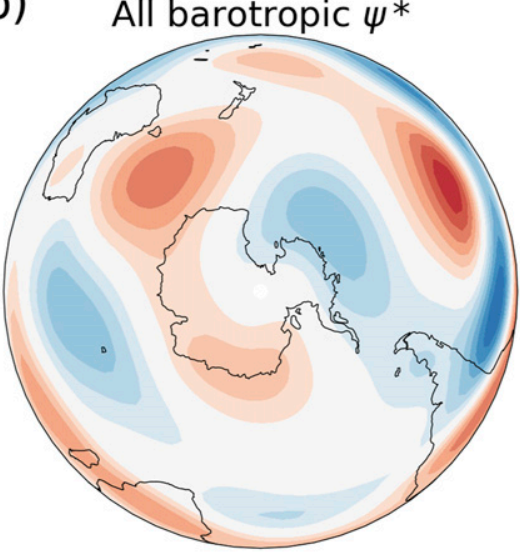

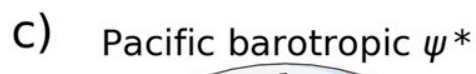

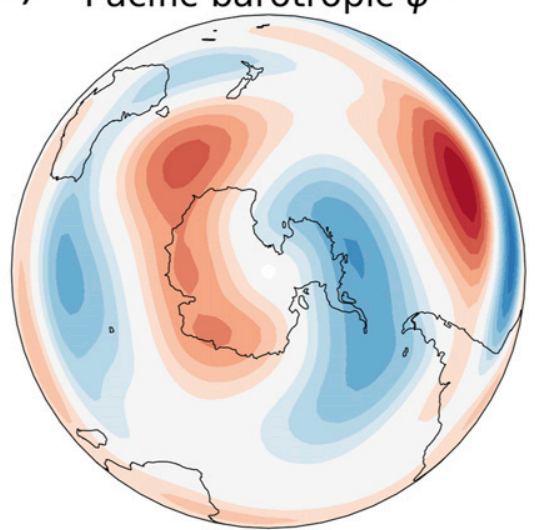

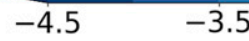

$-1.5$

$-0.5$

1.0

2.0

3.0

4.0

FIG. 8. Results of the barotropic model experiments. The multimodel mean stationary eddy streamfunction change is shown for (a) the full CMIP5 models (RCP8.5-Historical, on the 400-hPa level) along with (b) the mean of all barotropic model experiments with $S$ imposed at all longitudes, $0^{\circ}-35^{\circ} \mathrm{S}$. (c) As in (b), but for $S$ imposed only over the South Pacific $\left(150^{\circ}-80^{\circ} \mathrm{W}\right)$ region. The units are $10^{6} \mathrm{~m}^{2} \mathrm{~s}^{-1}$.

forcing region primarily amplifies the magnitude of the pattern (Fig. S6). The pattern associated with a bound of $20^{\circ} \mathrm{S}$ is very weak, suggesting that wave forcing from the region $20^{\circ}-30^{\circ} \mathrm{S}$ is most important. A further sensitivity concerns the choice of $400 \mathrm{hPa}$ as the equivalent barotropic level. Experiments performed using 300 and $500 \mathrm{hPa}$ are similar in many regards to the results for $400 \mathrm{hPa}$, including the cyclonic anomalies to the south of Australia and over the eastern Pacific and the anticyclonic anomaly through the Drake Passage (Figs. S2c and S3c). However, simulations using 300- and 500-hPa levels differ from one another in the sign of the stationary eddy streamfunction change at lower latitudes over northern Australia and the tropical western Pacific. The barotropic experiments are largely concerned with reproducing the response in the extratropics where the large-scale circulation is more barotropic, but it is worth noting this sensitivity.

Thus, far we have only considered the multimodel mean and so it is useful to consider the behavior of individual models. Figure 9 shows a selection of individual CMIP5 model responses to climate change (RCP8.5 - Historical) with their corresponding barotropic model run, with $S^{\prime}$ imposed over the South Pacific. Looking across the top panels, there is clearly a range of stationary wave behaviors, with the models varying in the magnitude and structure of the response. Common to each of these models is the cyclonic anomaly to the south of Australia, with an anticyclonic anomaly on the equatorward side, while there tends to be an anticyclonic anomaly on the opposite side near the Drake Passage (though the center of this anomaly varies in location; Figs. 9a-d). Encouragingly, the corresponding barotropic models capture the range of these responses relatively well, particularly the GFDL CM3 and HadGEM2-ES models. The barotropic model successfully reproduces the contrast between models with a high wavenumber response (EC-EARTH) and models with a lower wavenumber response (HadGEM2-ES). However, many of the details are not correctly captured, which is unsurprising given the simplicity of the approach. For example, the anomalies in the EC-EARTH model are shifted eastward and some are more or less pronounced than in the full model.

To gain more insight into the development of the stationary wave pattern, we plot the barotropic model response in the HadGEM2-ES model for the first 10 days after initialization (Fig. 10). After 1 day, anticyclonic and cyclonic anomalies have developed in the central and eastern tropical South Pacific respectively. The cyclonic anomaly expands eastward over the succeeding days, establishing a wave-1 pattern in the tropics by day 2 or 3 . Simultaneously, the anticyclonic anomaly propagates southeastward toward the Drake Passage. The cyclonic anomaly forming downstream of the original anticyclonic anomaly also develops a "tail", that drifts southwestward from days 2 to 5 . Eventually the end of this tail breaks off to form the cyclonic anomaly south of Australia, which is a common feature among CMIP5 models. It is possible that this anomaly is reinforced by the southeastward propagating wave, though this is not clear. The propagation of this tail upstream is consistent with the fact that long Rossby waves can propagate westward with respect to the flow. Finally, the full pattern is well established after only a week and only subtle details are modified over the next few days. Examination of other barotropic model runs yields a similar overall pattern of evolution.

In spite of the simplicity of the barotropic model approach it is clear that the model can capture the stationary wave response to climate change with relative success. Crucially it establishes the connection between tropical/subtropical wave sources and midlatitude circulation changes, showing that future stationary wave changes can be reproduced from changes in subtropical stationary wave sources without considering 

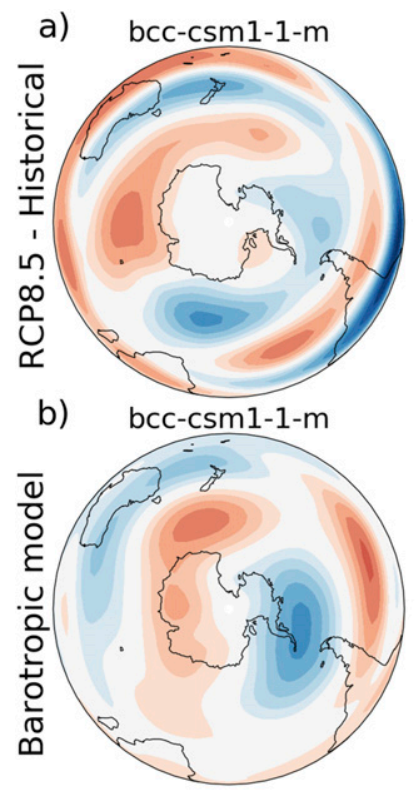

d)
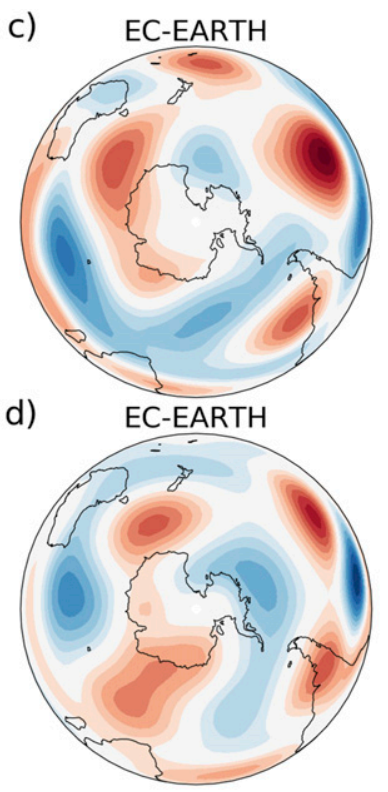

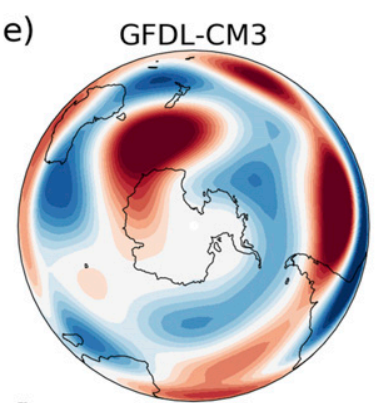

f)

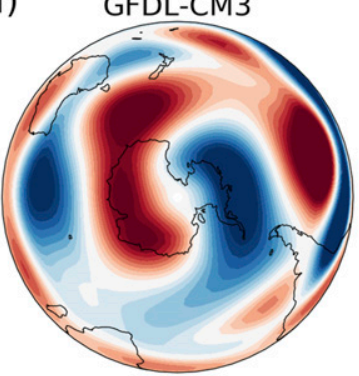

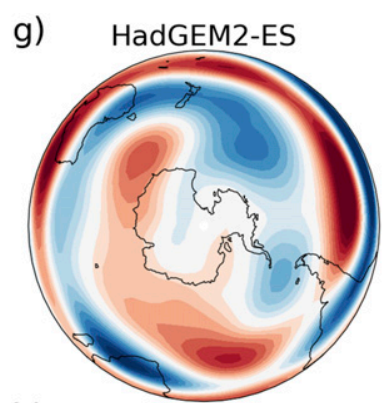

h)

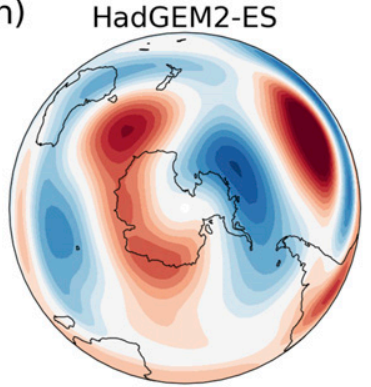

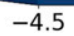

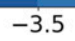

$-2.5$

$-1.5$

$-0.5$

1.0

2.0

3.0

4.0

FIG. 9. As in Fig. 8, but for individual models. (a),(c),(e),(g) The full CMIP5 model stationary eddy streamfunction change (RCP8.5Historical) is shown for four models, with (b),(d),(f),(h) the corresponding barotropic model results shown when the $S$ change has been imposed over the South Pacific. The units are $10^{6} \mathrm{~m}^{2} \mathrm{~s}^{-1}$.

changes in the zonal-mean flow. It should be noted, however, that the barotropic modeling method does not fully reproduce the changes to the zonal wind field (Fig. S7). Although the wintertime jet structure is substantially zonally asymmetric,
Simpson et al. (2014) showed that changes in transient eddy forcing in the winter season under climate change are largely zonally symmetric. Consequently, it appears that the $\mathrm{SH}$ extratropical zonal wind response to climate change is
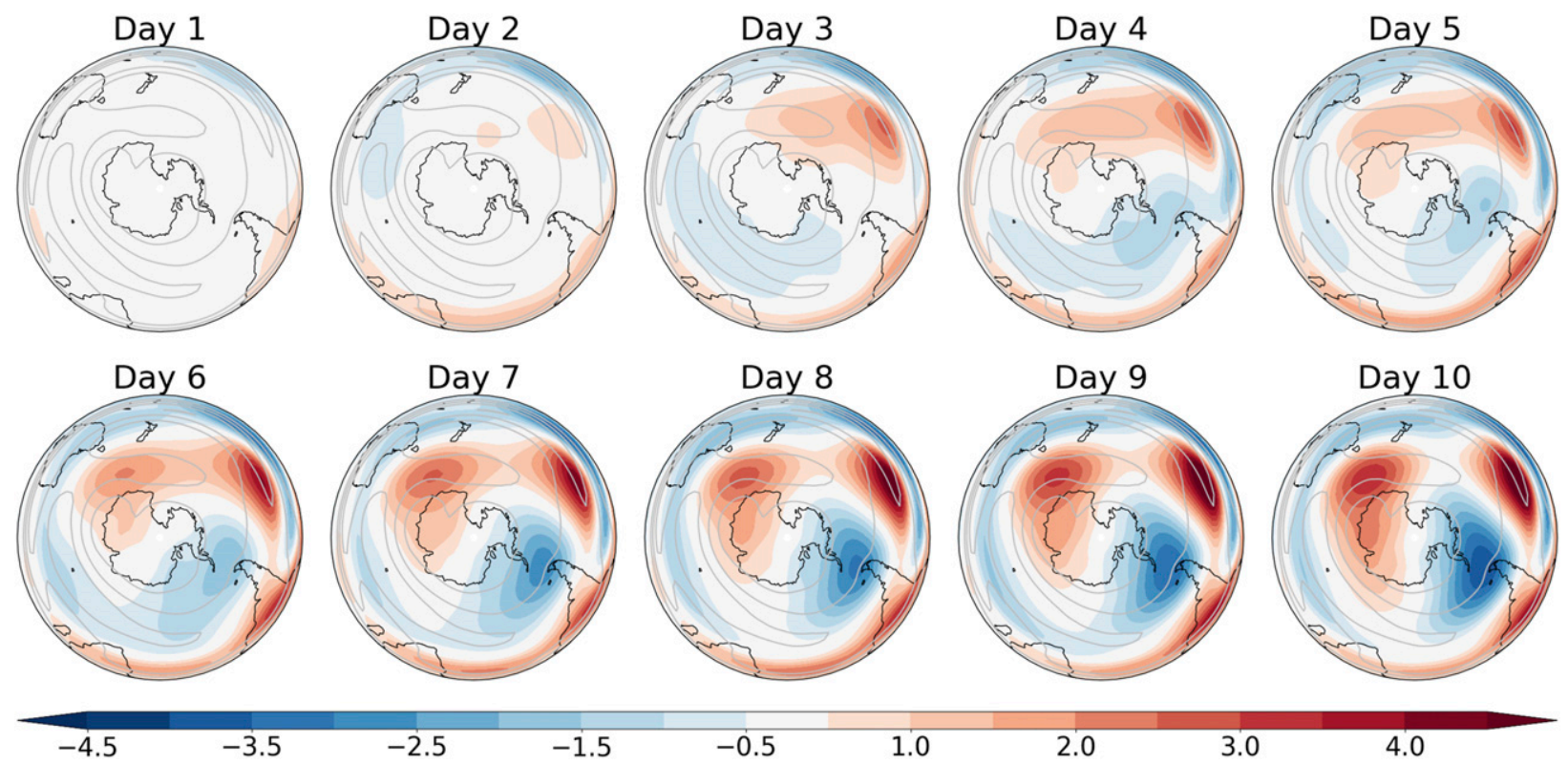

$$
-3.5
$$

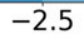

$-1.5$

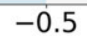

1.0

2.0

3.0

4.0

FIG. 10. Temporal evolution of the barotropic model response to $S$ changes using the Historical wind climatology and $S$ change in the HadGEM2-ES model. Gray contours show the Historical zonal wind climatology (contoured every $10 \mathrm{~m} \mathrm{~s}^{-1}$ ) and colors indicate the stationary eddy streamfunction anomaly on various days after the simulation begins. The units of the stationary eddy streamfunction change are $10^{6} \mathrm{~m}^{2} \mathrm{~s}^{-1}$. 
forced by both zonally symmetric and stationary wave components.

\section{Discussion and conclusions}

In this study we have investigated the stationary wave response to climate change in the SH winter. CMIP5 models consistently show a zonally asymmetric circulation response in this season, particularly characterized by a strengthening of the westerlies to the south of Australia and an enhanced subtropical jet over the eastern Pacific (Fig. 1b). Such a circulation response is likely to affect precipitation over Australia, New Zealand, and coastal Antarctica. Hence, understanding this mechanism will allow a better quantification of the drivers of uncertainty in future precipitation changes in these regions and inform how to reduce this uncertainty.

In terms of stationary waves, the response consists of a cyclonic anomaly to the south of Australia, an anticyclonic anomaly over Australia itself, and cyclonic flow over the subtropical eastern Pacific (Fig. 2c). The same pattern is reproduced in atmosphere-only simulations with the SSTs uniformly raised by $4 \mathrm{~K}$ (Fig. 2d). This shows that the pattern of stationary wave changes in these models is not particularly sensitive to the pattern of SST change, which is itself relatively uncertain, although the pattern of SST change will likely alter the details of the wave response. For example, the magnitude of the cyclonic anomaly south of Australia was found to depend on the zonal gradient of SST change in the tropical Pacific (Fig. 3f). That is, models with a more El Niñolike warming showed a weaker stationary wave response in the Australia region.

We then examined the mechanisms for the SH stationary wave response, noting that the projected southward shift of the Hadley cell edge and weakening of the Walker circulation are both correlated with the strength of the stationary wave response in a given model. In general, an El Niño-like warming of SSTs is associated with a contracted Hadley cell ( $\mathrm{Lu}$ et al. 2008). Hence, the fact that models with more El Niño-like warming patterns have a weaker SH stationary wave response is consistent with the less pronounced Hadley cell expansion in these models.

In a barotropic framework, stationary wave patterns can be altered either through changes to the source of Rossby waves or through changes to the background flow on which the waves propagate. We advanced the hypothesis that future changes to tropical and subtropical circulation patterns affect extratropical stationary waves through modification of the Rossby wave source $S$ (Fig. 6). Almost all models examined feature a future decrease in the magnitude of the climatological $S$ pattern over the eastern South Pacific, particularly in the subtropics (Fig. 5b). This is manifested as a meridional dipole structure resulting from a reduction in downwelling air at $20^{\circ} \mathrm{S}$ and a reduction in upwelling air at about $30^{\circ} \mathrm{S}$ (Figs. 3c,d). Combining the wave patterns associated with these eastern Pacific $S$ changes, using multiple regression analysis, successfully reproduced the multimodel mean stationary wave response (Fig. 7h), suggesting that these $S$ changes are the factor driving the wave response.
To confirm this we performed a set of barotropic model experiments in which we forced the barotropic model to have the same background state as the Historical climatology at $400 \mathrm{hPa}$ for a given CMIP5 model, and then imposed the future change in $S$ in the tropics and subtropics from that CMIP5 model. These experiments successfully reproduced many features of the multimodel mean, including the cyclonic anomaly to the south of Australia and anticyclonic anomaly over Australia (Fig. 8), and also captured some of the differences between individual models (Fig. 9). These simple experiments thus provide confirmation of the importance of $S$ changes in shaping the zonally asymmetric component of SH atmospheric circulation changes with climate change. On the other hand, the barotropic experiments did not fully capture all aspects of the stationary wave response, with some of the anomalies being shifted relative to the full CMIP5 model difference. These experiments did not account for the presence of orography over Antarctica, which has been shown to have an impact on SH stationary waves at high latitudes (Patterson et al. 2020; Goyal et al. 2021), although some information about the orography is implicitly present by imposing the climatological background state. Furthermore, in addition to changing $S$ patterns, stationary wave changes may occur via alterations of the basic state winds (e.g., through changes to the zonal mean jet), which alter the propagation characteristics of Rossby waves. Our barotropic model experiments did not consider this possibility, but an understanding of the relative importance of this mechanism could be obtained through the use of a stationary wave model, such as that employed by Simpson et al. (2016).

In conclusion, changes in tropical and subtropical circulation appear to be underlying causes of the wintertime SH stationary wave response to climate change, in particular the projected southward migration of the SH Hadley cell and the weakening of the Walker circulation. These influences are mediated through changes in $S$ that are particularly strong and robust across models in the eastern South Pacific. This study underlines the intimate connection between ostensibly disparate parts of the climate system, with low-latitude SST and circulation changes having farflung impacts. Consequently, understanding and constraining projections of future changes to tropical and subtropical climate is crucial for making accurate projections of the $\mathrm{SH}$ extratropics.

Acknowledgments. We thank the three reviewers for their insightful comments that helped to substantially improve this manuscript. We acknowledge World Climate Research Programme's Working Group on Coupled Modelling, which is responsible for CMIP and also ECMWF for making available ERA-Interim data. We also thank the climate modeling groups (listed in the online supplemental material) for producing and making available their model output. MP was funded by the Natural Environment Research Council (Grant NE/L002612/1). Much of the content in this study forms a part of MP's PhD thesis. TJB was supported by the Natural Environment Research Council as part of the British Antarctic Survey research programme Polar Science for Planet Earth.

Data availability statement. CMIP5 data for the work in this paper were obtained from the BADC archive on the CEDA 
data server (available at http://data.ceda.ac.uk/badc/), and the ERA-Interim data were downloaded from the ECMWF website (https://www.ecmwf.int/en/forecasts/datasets/browsereanalysis-datasets).

\section{REFERENCES}

al Fahad, A., N. J. Burls, and Z. Strasberg, 2020: How will Southern Hemisphere subtropical anticyclones respond to global warming? Mechanisms and seasonality in CMIP5 and CMIP6 model projections. Climate Dyn., 55, 703-718, https://doi.org/10.1007/ s00382-020-05290-7.

Ambrizzi, T., and B. J. Hoskins, 1997: Stationary Rossby-wave propagation in a baroclinic atmosphere. Quart. J. Roy. Meteor. Soc., 123, 919-928, https://doi.org/10.1002/qj.49712354007.

Barnes, E. A., and L. Polvani, 2013: Response of the midlatitude jets, and of their variability, to increased greenhouse gases in the CMIP5 models. J. Climate, 26, 7117-7135, https://doi.org/ 10.1175/JCLI-D-12-00536.1.

Bayr, T., D. Dommenget, T. Martin, and S. B. Power, 2014: The eastward shift of the Walker circulation in response to global warming and its relationship to ENSO variability. Climate Dyn., 43, 2747-2763, https://doi.org/10.1007/s00382-014-2091-y.

Bracegirdle, T. J., E. Shuckburgh, J.-B. Sallee, Z. Wang, A. J. S. Meijers, N. Bruneau, T. Phillips, and L. J. Wilcox, 2013: Assessment of surface winds over the Atlantic, Indian, and Pacific Ocean sectors of the Southern Ocean in CMIP5 models: Historical bias, forcing response, and state dependence. J. Geophys. Res., 118, 547-562, https://doi.org/10.1002/ jgrd.50153.

— J J. Turner, J. S. Hosking, and T. Phillips, 2014: Sources of uncertainty in projections of twenty-first-century westerly wind changes over the Amundsen Sea, West Antarctica, in CMIP5 climate models. Climate Dyn., 43, 2093-2104, https:// doi.org/10.1007/s00382-013-2032-1.

Brandefelt, J., and H. Körnich, 2008: Northern Hemisphere stationary waves in future climate projections. J. Climate, $\mathbf{2 1}$ 6341-6353, https://doi.org/10.1175/2008JCLI2373.1.

Ceppi, P., and D. L. Hartmann, 2013: On the speed of the eddydriven jet and the width of the Hadley cell in the Southern Hemisphere. J. Climate, 26, 3450-3465, https://doi.org/10.1175/ JCLI-D-12-00414.1.

Chenoli, S. N., M. Y. Ahmad Mazuki, J. Turner, and A. A. Samah, 2017: Historical and projected changes in the Southern Hemisphere sub-tropical jet during winter from the CMIP5 models. Climate Dyn., 48, 661-681, https://doi.org/10.1007/ s00382-016-3102-y.

Dee, D. P., S. M. Uppala, A. J. Simmons, P. Berrisford, P. Poli, and S. Kobayashi, 2011: The ERA-Interim reanalysis: Configuration and performance of the data assimilation system. Quart. J. Roy. Meteor. Soc., 137, 553-597, https://doi.org/10.1002/qj.828.

Ding, Q., E. J. Steig, D. S. Battisti, and M. Küttel, 2011: Winter warming in West Antarctica caused by central tropical Pacific warming. Nat. Geosci., 4, 398-403, https://doi.org/10.1038/ ngeo1129.

Freitas, A. C. V., and V. B. Rao, 2014: Global changes in propagation of stationary waves in a warming scenario. Quart. J. Roy. Meteor. Soc., 140, 364-383, https://doi.org/10.1002/qj.2151.

, J. S. Frederiksen, T. J. O'Kane, and T. Ambrizzi, 2017: Simulated austral winter response of the Hadley circulation and stationary Rossby wave propagation to a warming climate. Climate Dyn., 49, 521-545, https://doi.org/10.1007/ s00382-016-3356-4.
Gastineau, G., L. Li, and H. Le Treut, 2009: The Hadley and Walker circulation changes in global warming conditions described by idealized atmospheric simulations. J. Climate, 22, 3993-4013, https://doi.org/10.1175/2009JCLI2794.1.

Goyal, R., M. Jucker, A. Sen Gupta, and M. H. England, 2021: Generation of the Amundsen Sea low by Antarctic orography. Geophys. Res. Lett., 48, e2020GL091 487, https://doi.org/ 10.1029/2020GL091487.

Grise, K. M., and L. M. Polvani, 2014: The response of midlatitude jets to increased $\mathrm{CO}_{2}$ : Distinguishing the roles of sea surface temperature and direct radiative forcing. Geophys. Res. Lett., 41, 6863-6871, https://doi.org/10.1002/2014GL061638.

Haarsma, R. J., and F. Selten, 2012: Anthropogenic changes in the Walker circulation and their impact on the extra-tropical planetary wave structure in the Northern Hemisphere. Climate Dyn., 39, 1781-1799, https://doi.org/10.1007/s00382-012-1308-1.

He, J., and B. J. Soden, 2015: Anthropogenic weakening of the tropical circulation: The relative roles of direct $\mathrm{CO}_{2}$ forcing and sea surface temperature change. J. Climate, 28, 8728-8742, https://doi.org/10.1175/JCLI-D-15-0205.1.

Held, I. M., and B. J. Soden, 2006: Robust responses of the hydrological cycle to global warming. J. Climate, 19, 5686-5699, https://doi.org/10.1175/JCLI3990.1.

— , P. L. Panetta, and R. T. Pierrehumbert, 1985: Stationary external Rossby waves in vertical shear. J. Atmos. Sci., 42, 865-883, https://doi.org/10.1175/1520-0469(1985)042<0865: SERWIV $>2.0 . \mathrm{CO} ; 2$.

Holland, P. R., T. J. Bracegirdle, P. Dutrieux, A. Jenkins, and E. J. Steig, 2019: West Antarctic ice loss influenced by internal climate variability and anthropogenic forcing. Nat. Geosci., 12, 718-724, https://doi.org/10.1038/s41561-019-0420-9.

Hoskins, B. J., and T. Ambrizzi, 1993: Rossby wave propagation on a realistic longitudinally varying flow. J. Atmos. Sci., 50, 1661-1671, https://doi.org/10.1175/1520-0469(1993)050<1661: RWPOAR $>2.0 . \mathrm{CO} ; 2$.

Inatsu, M., and B. J. Hoskins, 2004: The zonal asymmetry of the Southern Hemisphere winter storm track. J. Climate, 17, 48824892, https://doi.org/10.1175/JCLI-3232.1.

Joseph, R., M. Ting, and P. J. Kushner, 2004: The global stationary wave response to climate change in a coupled GCM. J. Climate, 17, 540-556, https://doi.org/10.1175/1520-0442(2004) 017<0540:TGSWRT>2.0.CO;2.

Kang, S. M., and J. Lu, 2012: Expansion of the Hadley cell under global warming: Winter versus summer. J. Climate, 25, 83878393, https://doi.org/10.1175/JCLI-D-12-00323.1.

Lee, S. K., C. R. Mechoso, C. Wang, and J. D. Neelin, 2013: Interhemispheric influence of the northern summer monsoons on southern subtropical anticyclones. J. Climate, 26, $10193-$ 10 204, https://doi.org/10.1175/JCLI-D-13-00106.1.

Li, W., and Coauthors, 2013: Intensification of the Southern Hemisphere summertime subtropical anticyclones in a warming climate. Geophys. Res. Lett., 40, 5959-5964, https://doi.org/ 10.1002/2013GL058124.

Li, X., D. M. Holland, E. P. Gerber, and C. Yoo, 2014: Impacts of the north and tropical Atlantic Ocean on the Antarctic Peninsula and sea ice. Nature, 505, 538-542, https://doi.org/ 10.1038/nature12945.

— E. P. Gerber, D. M. Holland, and C. Yoo, 2015: A Rossby wave bridge from the tropical Atlantic to West Antarctica. J. Climate, 28, 2256-2273, https://doi.org/10.1175/JCLI-D-1400450.1.

Lorenz, D. J., and E. T. DeWeaver, 2007: Tropopause height and zonal wind response to global warming in the IPCC scenario 
integrations. J. Geophys. Res., 112, D10 119, https://doi.org/ 10.1029/2006JD008087.

Lu, J., G. A. Vecchi, and T. Reichler, 2007: Expansion of the Hadley cell under global warming. Geophys. Res. Lett., 34, L06805, https://doi.org/10.1029/2006GL028443.

—, G. Chen, and D. M. W. W. Frierson, 2008: Response of the zonal mean atmospheric circulation to El Niño versus global warming. J. Climate, 21, 5835-5851, https://doi.org/10.1175/ 2008JCLI2200.1.

Ma, J., and S.-P. Xie, 2013: Regional patterns of sea surface temperature change: A source of uncertainty in future projections of precipitation and atmospheric circulation. J. Climate, 26, 2482-2501, https://doi.org/10.1175/JCLI-D-12-00283.1.

,-- , and Y. Kosaka, 2012: Mechanisms for tropical tropospheric circulation change in response to global warming. J. Climate, 25, 2979-2994, https://doi.org/10.1175/JCLI-D-1100048.1.

Manabe, S., and R. J. Stouffer, 1980: Sensitivity of a global climate model to an increase of $\mathrm{CO}_{2}$ concentration in the atmosphere. J. Geophys. Res., 85, 5529, https://doi.org/10.1029/ JC085iC10p05529.

Meinshausen, M., and Coauthors, 2011: The RCP greenhouse gas concentrations and their extensions from 1765 to 2300 . Climatic Change, 109, 213-241, https://doi.org/10.1007/s10584011-0156-z.

Mindlin, J., T. G. Shepherd, C. S. Vera, M. Osman, G. Zappa, R. W. Lee, and K. I. Hodges, 2020: Storyline description of Southern Hemisphere midlatitude circulation and precipitation response to greenhouse gas forcing. Climate Dyn., 54, 4399-4421, https://doi.org/10.1007/s00382-020-05234-1.

Mo, K. C., and R. W. Higgins, 1998: The Pacific-South American modes and tropical convection during the Southern Hemisphere winter. Mon. Wea. Rev., 126, 1581-1596, https://doi.org/10.1175/ 1520-0493(1998)126<1581:TPSAMA > 2.0.CO;2.

Patterson, M., T. Bracegirdle, and T. Woollings, 2019: Southern Hemisphere atmospheric blocking in CMIP5 and future changes in the Australia-New Zealand sector. Geophys. Res. Lett., 46, 9281-9290, https://doi.org/10.1029/2019GL083264.

—, T. Woollings, T. J. Bracegirdle, and N. T. Lewis, 2020: Wintertime Southern Hemisphere jet streams shaped by interaction of transient eddies with Antarctic orography. $J$. Climate, 33, 10 505-10 522, https://doi.org/10.1175/JCLI-D-200153.1.

Power, S. B., F. Delage, R. Colman, and A. Moise, 2012: Consensus on twenty-first-century rainfall projections in climate models more widespread than previously thought. J. Climate, 25, 3792-3809, https://doi.org/10.1175/JCLI-D-11-00354.1.

Previdi, M., and B. G. Liepert, 2007: Annular modes and Hadley cell expansion under global warming. Geophys. Res. Lett., 34, L22701, https://doi.org/10.1029/2007GL031243.

Sardeshmukh, P., and B. Hoskins, 1988: The generation of global rotational flow by steady idealized tropical divergence. J. Atmos. Sci., 45, 1228-1250, https://doi.org/10.1175/1520-0469(1988) 045<1228:TGOGRF $>2.0$.CO;2.
Shaw, T. A., 2019: Mechanisms of future predicted changes in the zonal mean mid-latitude circulation. Curr. Climate Change Rep., 5, 345-357, https://doi.org/10.1007/s40641-019-00145-8.

Shepherd, T. G., 2014: Atmospheric circulation as a source of uncertainty in climate change projections. Nat. Geosci., 7, 703708, https://doi.org/10.1038/ngeo2253.

Simpson, I. R., T. A. Shaw, and R. Seager, 2014: A diagnosis of the seasonally and longitudinally varying mid-latitude circulation response to global warming. J. Atmos. Sci., 71, 2489-2515, https://doi.org/10.1175/JAS-D-13-0325.1.

- R. Seager, M. Ting, and T. A. Shaw, 2016: Causes of change in Northern Hemisphere winter meridional winds and regional hydroclimate. Nat. Climate Change, 6, 65-70, https://doi.org/ 10.1038/nclimate2783.

Song, F., L. R. Leung, J. Lu, and L. Dong, 2018: Seasonally dependent responses of subtropical highs and tropical rainfall to anthropogenic warming. Nat. Climate Change, 8, 787-792, https://doi.org/10.1038/s41558-018-0244-4.

Swart, N. C., and J. C. Fyfe, 2012: Observed and simulated changes in the Southern Hemisphere surface westerly windstress. Geophys. Res. Lett., 39, L16711, https://doi.org/10.1029/ 2012GL052810.

Taylor, K. E., D. Williamson, and F. Zwiers, 2000: The sea surface temperature and sea-ice concentration boundary conditions for AMIP II simulations. PCMDI Rep. 60, 20 pp.

$\longrightarrow$, R. J. Stouffer, and G. A. Meehl, 2012: An overview of CMIP5 and the experiment design. Bull. Amer. Meteor. Soc., 93, 485498, https://doi.org/10.1175/BAMS-D-11-00094.1.

Tebaldi, C., J. M. Arblaster, and R. Knutti, 2011: Mapping model agreement on future climate projections. Geophys. Res. Lett., 38, L23701, https://doi.org/10.1029/2011GL049863.

Turner, J., 2004: The El Niño-Southern Oscillation and Antarctica. Int. J. Climatol., 24 (1), 1-31, https://doi.org/10.1002/joc.965.

Vallis, G. K., P. Zurita-Gotor, C. Cairns, and J. Kidston, 2015: Response of the large-scale structure of the atmosphere to global warming. Quart. J. Roy. Meteor. Soc., 141, 1479-1501, https://doi.org/10.1002/qj.2456.

Vecchi, G. A., and B. J. Soden, 2007: Global warming and the weakening of the tropical circulation. J. Climate, 20, 43164340, https://doi.org/10.1175/JCLI4258.1.

Xie, S.-P., 2020: Ocean warming pattern effect on global and regional climate change. AGU Adv., 1, e2019AV000130, https:// doi.org/10.1029/2019AV000130.

—, C. Deser, G. A. Vecchi, J. Ma, H. Teng, and A. T. Wittenberg, 2010: Global warming pattern formation: Sea surface temperature and rainfall. J. Climate, 23, 966-986, https://doi.org/10.1175/2009JCLI3329.1.

Yang, S., and P. J. Webster, 1990: The effect of summer tropical heating on the location and intensity of the extratropical westerly jet streams. J. Geophys. Res., 95, 18705-18721, https://doi.org/10.1029/JD095iD11p18705.

Zappa, G., and T. G. Shepherd, 2017: Storylines of atmospheric circulation change for European regional climate impact assessment. J. Climate, 30, 6561-6577, https://doi.org/10.1175/ JCLI-D-16-0807.1. 